Article

\title{
An Integrated Risk Index Model Based on Hierarchical Fuzzy Logic for Underground Risk Assessment
}

\author{
Muhammad Fayaz ${ }^{1}$, Israr Ullah ${ }^{1}$, Dong-Hwan Park ${ }^{2}$, Kwangsoo Kim ${ }^{2}$ and DoHyeun Kim ${ }^{1, *}$ \\ 1 Department of Computer Engineering, Jeju National University, Jeju 63243, Korea; \\ hamaz_khan@yahoo.com (M.F.); israr.ullah@jejunu.ac.kr (I.U.) \\ 2 ETRI, 218 Gajenong-ro Yuseung-Gu, Daejeon 34129, Korea; dhpark@etri.re.kr (D.-H.P.); \\ enoch@etri.re.kr (K.K.) \\ * Correspondence: kimdh@jejunu.ac.kr; Tel.: +82-064-754-3658
}

Received: 7 September 2017; Accepted: 7 October 2017; Published: 11 October 2017

\begin{abstract}
Available space in congested cities is getting scarce due to growing urbanization in the recent past. The utilization of underground space is considered as a solution to the limited space in smart cities. The numbers of underground facilities are growing day by day in the developing world. Typical underground facilities include the transit subway, parking lots, electric lines, water supply and sewer lines. The likelihood of the occurrence of accidents due to underground facilities is a random phenomenon. To avoid any accidental loss, a risk assessment method is required to conduct the continuous risk assessment and report any abnormality before it happens. In this paper, we have proposed a hierarchical fuzzy inference based model for under-ground risk assessment. The proposed hierarchical fuzzy inference architecture reduces the total number of rules from the rule base. Rule reduction is important because the curse of dimensionality damages the transparency and interpretation as it is very tough to understand and justify hundreds or thousands of fuzzy rules. The computation time also increases as rules increase. The proposed model takes 175 rules having eight input parameters to compute the risk index, and the conventional fuzzy logic requires 390,625 rules, having the same number of input parameters to compute risk index. Hence, the proposed model significantly reduces the curse of dimensionality. Rule design for fuzzy logic is also a tedious task. In this paper, we have also introduced new rule schemes, namely maximum rule-based and average rule-based; both schemes can be used interchangeably according to the logic needed for rule design. The experimental results show that the proposed method is a virtuous choice for risk index calculation where the numbers of variables are greater.
\end{abstract}

Keywords: fuzzy logic; risk index; sewerage supply; underground structure; water supply

\section{Introduction}

Underground space and structures are hard to monitor because access to most of the underground facilities is difficult or almost impossible. Many issues are associated with underground facilities, such as leakage, liquefaction, collapse, distortion, and floods. Underground risk has to be evaluated periodically so that high-risk areas can be sustained in a timely fashion in order to make certain the protection of the people [1].

Different ways exist for assessing underground risks, such as assertion, sustainability, safety, and the environment; these are portrayed by risk ratings, such as high, low, or medium. The risk score is based on different criteria, it can be aggregated in order to find overall risk. Using overall risk the maintenance priority can be determined. Normally, underground risk assessment needs a large number of subjective judgments from the experts; these types of assessments are costly and time-consuming. 
Due to the complex non-linear relationship between the risk score and the risk mathematical rating, if a model is designed for this process in order to assess underground risk, it will be obviously of great benefit to underground agencies and Geo-environmental Engineers. These models can assess underground risk within no time or cost $[2,3]$.

An amount of construction accidents comprised of the failure of major infrastructure facilities, i.e., subways, bridges, and buildings, have happened because of less effective underground assessment. Hence, it is very obligatory to assess underground risk periodically in order to avoid these accidents. Most massive underground projects have a complex sequence of events and have complex procedural systems. For example, the rock mass is very complex and its association is with large suspicions. It is also very difficult to solve decision problems with underground construction and may lead to unforeseen results. When seeking to make improvements, the probabilistic decision and risk analysis can be used. The underground risk is an important element, and many qualitative and quantitative risk methods are available for risk assessment. To make a trustworthy decision, it is necessary to know the risk of the given system or procedure correctly [4].

Fuzzy logic is the most popular risk assessment and is a risk analysis method that can be deployed in almost any field [5,6]. Fuzzy logic is a type of logic with many values, in which the range of truth values lies between 0 and 1. Fuzzy logic is opposed to Boolean logic in which the truth values of variables may only be the numerical values 0 or 1 . Fuzzy logic has been deployed to deal with incomplete truth, where the true value may be totally true or totally untrue [7]. Many research efforts have also been done for designing fuzzy logic with a special structure to solve the curse of dimensionality. Hierarchal fuzzy systems have been designed in order to solve the exponential increase of rules based on the number of inputs entered into the system. The size of hierarchical fuzzy logic can be characterized by different modules that are carried out as a computational contribution to the final solution. Low-level modules have some input variables and the output of the same can be used as input variables to the high-level module for the last solution. The key benefit of the construction of hierarchical fuzzy systems is the obligation of fewer rules as compared to the monolithic fuzzy system. In conventional fuzzy logic, the number of rules may increase exponentially as the number of system variables increases; hence, the conventional fuzzy logic is not applicable in the case of a large number of input variables [8-10].

The objective of this paper is to design a fuzzy logic with a special structure to handle the curse of dimensionality. Underground risk assessment is very complex due to several parameters. In order to accurately assess the risk of a location, the maximum number of parameters should be taken into account. In the proposed work, eight parameters have been considered for underground risk assessment. The conventional fuzzy logic is not a good choice for the underground risk assessment. The main problem faced by conventional fuzzy logic systems is the exponential increase in the number of rules with growth in the number of variables entering into the system. It becomes difficult to tackle a large number of rules, and it has also a great influence on the performance of the system. This minor error in rule design may lead to uncertain results. Rule design is time-consuming and requires attention. There is a need for a model with a special structure that can reduce accidents to a minimum level and make risk assessment faster and easier. The structure of the paper is organized as: Section 2 presents the related work. A new hierarchal fuzzy model for the underground risk assessment is developed in Section 3. Section 4 shows and explains experimental results. The paper is concluded in Section 5.

\section{Related Work}

Many attempts have been made for underground risk assessment over the last few decades. Some of the major contributions have been reported here.

Large underground projects are normally very complex and have complicated technical systems. One example is the rock mass which is very complicated and related to large uncertainties. Any wrong decision may lead to annoying risks. In order to ease the decision-making, probabilistic decision and risk analysis can be used. Sturk et al. explained a decision procedure valuable for underground decision problems and described some existing approaches for decision and risk investigation. The application 
of these methods has been done to particular problems associated with the Stockholm Ring Road project [1].

It is very difficult to operate underground, hence regular inspection and monitoring of damage growth are very obligatory. Kleta et al. presented an overview of potential solutions, criteria, and algorithms for the different types of damages and some suggestions for numerical description of their size. Many examples are given for brick lining surfaces and concentrate analysis. Dripstones, which are the first symptoms of the initial phase of damage, can be recognized on the basis of color difference. For crack identification, dark lines of the most irregular character can be used. For the identification of large cavities, texture patterns can be used. Color enhancement is the easiest way for detecting damage presentation and for automatic damage measurement of different parameters such as length, area, or width. In various cases, poor quality of the input video streaming reduces the quality of the image; therefore, the augmented reality, which is an image enhancement method, can be used to significantly reduce the influence of disturbance [11]. Many authors have used image processing techniques for underground structure monitoring, such as for structure health monitoring [12,13], displacement monitoring [14], and development in underground structure and crack monitoring $[15,16]$.

Numerous risk assessment methodologies have been proposed in various areas. Road tunnel assessment is also very important and a lot of research has been done for tunnel assessment. The urban area road tunnels are very busy, and hence it is very difficult to monitor the operations of road tunnels in urban areas. A methodology named Quantity Risk Assessment (QRA) has been proposed for risk assessment in the road tunnels of urban areas. The QRA models used six events, namely, fire, flooding, chain, collision, tunnel collapse, explosion, and spillage, for risk assessment in the tunnels of urban areas [17,18]. Meng et al. in [19] suggested a novel Quantitative Risk Assessment (QRA) model to calculate the risks of non-homogenous urban road tunnels, because the existing QRA models for road tunnels are inapplicable in the road tunnels. This technique uses principle named technical segmentation principle in which the roads of the urban area are divided into many similar sections. For each section of the road tunnel, the individual risk is defined and also the collaborative risk for the whole tunnel is defined. The article then proceeds to develop a new QRA model for each of the homogeneous sections.

The fuzzy logic is also a very significant tool for risk assessment and analysis. Several scientists have used the fuzzy logic for risk assessment in different areas. Blockley et al. in [20] proposed fuzzy concepts, such as fuzzification, membership functions, union, implication, aggregation, defuzzification, size of parameters, total, effect of parameters, membership level, fuzzy sets, intersection of two variables, a maximum of two variables, and a minimum of two variables for the first time in structural engineering. These concepts help the engineers with risk analysis. Cho et al. in [21] introduced Fuzzy Event Tree Analysis (FETA) for identification of events that cause failures of temporary structure and to prevent their failure during construction. Similarly, Fujino in [22] introduced the application of fuzzy fault tree analysis to side accidents of some simple cases of construction. Wang et al. in [4] proposed a method for bridge risk assessment; they developed an Adaptive Neuro Fuzzy Inference System (ANFIS) in order to assess bridge risk using 506 bridge maintenance projects. This method can assist the Highway Agency to maintain risks in a timely manner. This method is very useful and economical for risk assessment as compared to the existing risk assessment methods which need a huge amount of subjective judgment from bridge experts. They have made the comparison of ANFIS with Artificial Neural Network (ANN) and Multiple Regression Analysis (MRA). The results indicate that the ANFIS outperformed Artificial Neural Network (ANN) and Multiple Regression Analysis (MRA).

Kim et al. in [23] introduced the UGS middle-ware (UGS-M) for underground safety support. The UGS-M has the following components: resource manager, monitoring manager, sensing data manager, communication manager, and data translator. The key role of the UGS-M was the abstraction of sensing devices installed underground. The reason behind the deployment of UGS-M was to provide a powerful tool for improving of the capability to monitor the underground environment and also efficiently enhance the underground safety management. 
Despite the improvements in the methods of underground risk assessment, there is a need for an efficient method that can reduce accidents to a minimum level and make risk assessment easier.

\section{Proposed Integrated Risk Index Model}

The main challenge of the hierarchical fuzzy inference system is to design a full architecture with minimum rules. In this work, we have to take into account 8 parameters; if conventional fuzzy logic is designed for such system, its computational complexity will be high, because computation complexity increases exponentially as new perimeters enter into the system. In this work, we have designed a model named integrated risk index model, which is based on the hierarchical fuzzy model. Due to the hierarchical decomposition, the proposed fuzzy system is called hierarchical fuzzy system. Rendering to their roles, the rules are grouped into the modules in the system. Each module performs the computation of partial solution, and these fractional solutions are used in next succeeding modules to calculate the concluding output of the system. Though calculation in modules is achieved through fuzzy rules, the decomposition of the flat and large rule base into numerous small rule bases (each with only a few variables) shrinks the complete number of rules.

The Figure 1 illustrates the hierarchical fuzzy logic architecture for the risk assessment for the UGS system. Four hierarchical levels are present in the proposed architecture for underground risk assessment: input layer (level-3), Blended Layer (layer-2), Collaborative layer (Level-1), and Integrated Risk layer (Layer-0). Total of 7 sub fuzzy logics have been used in this model; the input layer has eight input parameters, namely, water supply risk probability $\left(X_{1}\right)$, water supply risk severity $\left(X_{2}\right)$, sewerage supply risk probability $\left(X_{3}\right)$, sewerage supply risk severity $\left(X_{4}\right)$, metro structure risk probability $\left(X_{5}\right)$, metro structure risk severity $\left(X_{6}\right)$, Geo-environmental risk probability $\left(X_{7}\right)$, and Geo-environmental risk severity $\left(X_{8}\right)$. The blended layer has four fuzzy inference systems: M1_FIS, M2_FIS, $M_{3}$ FIS, and G_FIS, which are abbreviated for water supply pipeline risk index $\left(\mathrm{M}_{1}\right)$ fuzzy logic, sewerage supply pipeline risk index $\left(\mathrm{M}_{2}\right)$ fuzzy logic, metro structure risk index $\left(\mathrm{M}_{3}\right)$ fuzzy logic, and Geo-environmental risk index $(\mathrm{G})$ fuzzy logic, respectively. The collaborative layer has two fuzzy logics, namely, collaborative risk index 1 fuzzy logic ( $\mathrm{CR}_{1}$ FIS) and collaborative risk 2 fuzzy logic $\left(\mathrm{CR}_{2}\right.$ FIS). Similarly, the integrated layer has integrated risk fuzzy logic (FIS_IR); this is the final output of the proposed hierarchical fuzzy inference system architecture. Water supply risk probability and water supply risk severity are inputs to FIS_M1. Inputs to FIS_M $\mathrm{M}_{2}$ are sewerage risk probability and sewerage risk severity. The metro structure risk probability and metro structure risk severity are inputs to the FIS_M $\mathrm{M}_{3}$; similarly, the FIS_G takes Geo-environmental risk probability and Geo-environmental risk severity as inputs. Further, the output

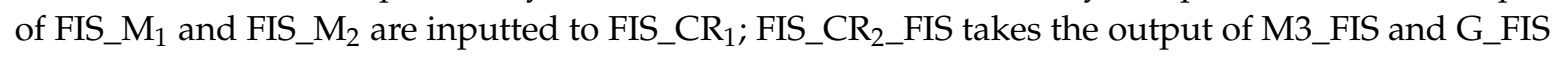
as inputs. The purpose of the proposed model is to take into account all the parameters to calculate a centric risk value using fuzzy logic, hence an integrated risk fuzzy logic (FIS_IR) is used. The output of IR_FIS is the final risk value of hierarchical fuzzy logic for underground risk. The structure diagram for the proposed model is given in Figure 1, and the structure diagram of the conventional logic has the same number of input parameters as given in Figure 2.

Mamdani fuzzy logic has been used in the proposed hierarchical model. Mamdani fuzzy rules are too simple and more useful as compared to the Takagi-Sugeno-Kang method. Mamdani fuzzy logic is comprised of the fuzzifier, knowledge base, inference engine, and defuzzifier modules. The fuzzifier takes crisp values as input and generates fuzzy values using membership functions. After each rule evaluation inside the knowledge base, the aggregation of each consequent membership function values is carried out using maximum operation. The defuzzification method converts the fuzzy consequents into crisp value [24]. Membership functions play a very vital role in fuzzy logic construction and operations; there are many types of membership functions, such as triangular, Gaussian, Bell-shaped, and Sigmoid (right, left, difference, etc.). In the proposed approach we have used the triangular membership function which is the most common and effective membership function used in fuzzy logic [25]. The fuzzy logic consisted of input and output variables and many membership functions can be defined for each input/output variable. In the proposed approach, five membership functions 
have been defined for each input/output variable; for consistency, we have defined the same number of membership functions for each variable in all fuzzy logics. The labelling has also been carried out in the same manner and identical labels (linguistic terms) are assigned to the membership functions of all variables of the proposed model. The linguistic terms that are defined for membership functions are $\mathrm{VL}, \mathrm{L}, \mathrm{M}, \mathrm{H}$, and $\mathrm{VH}$, which are abbreviations for very low, low, medium, high, and very high.

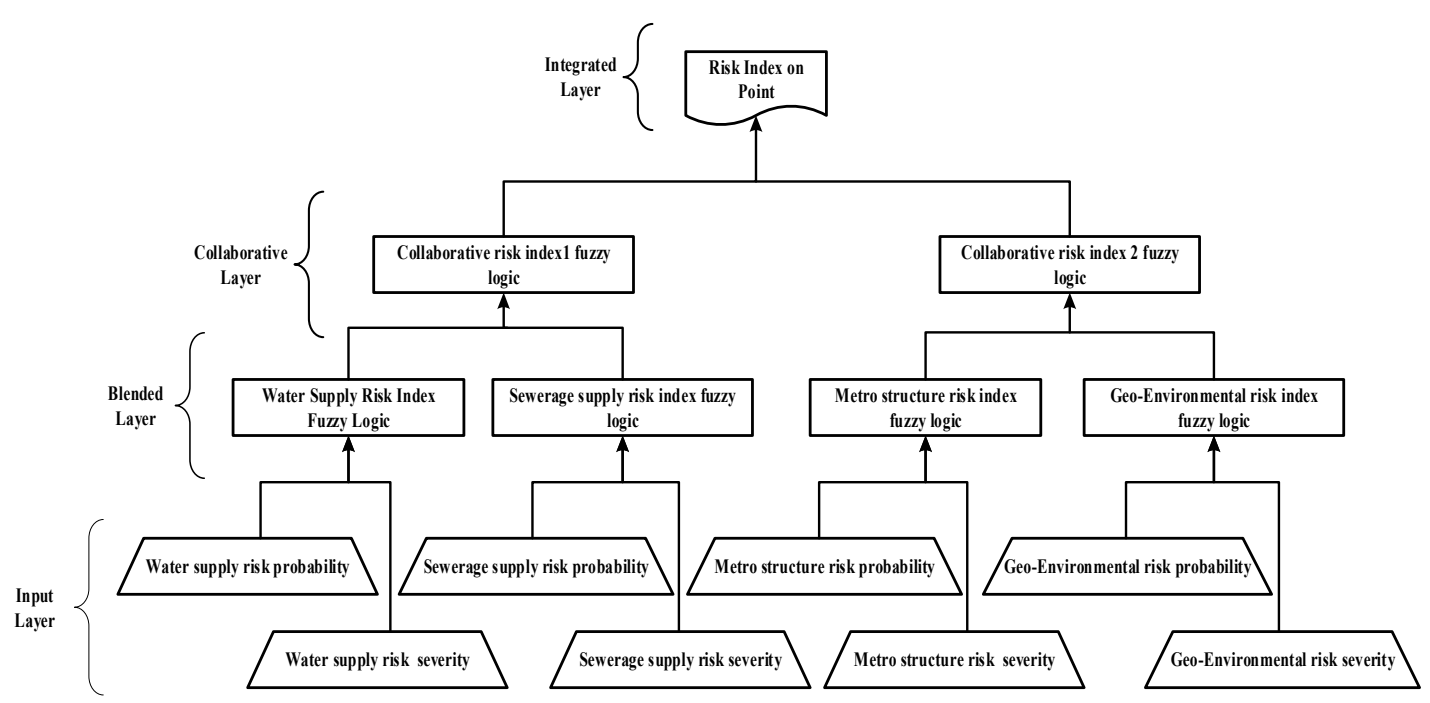

Figure 1. An integrated risk index model based on hierarchical fuzzy logic for underground risk assessment.

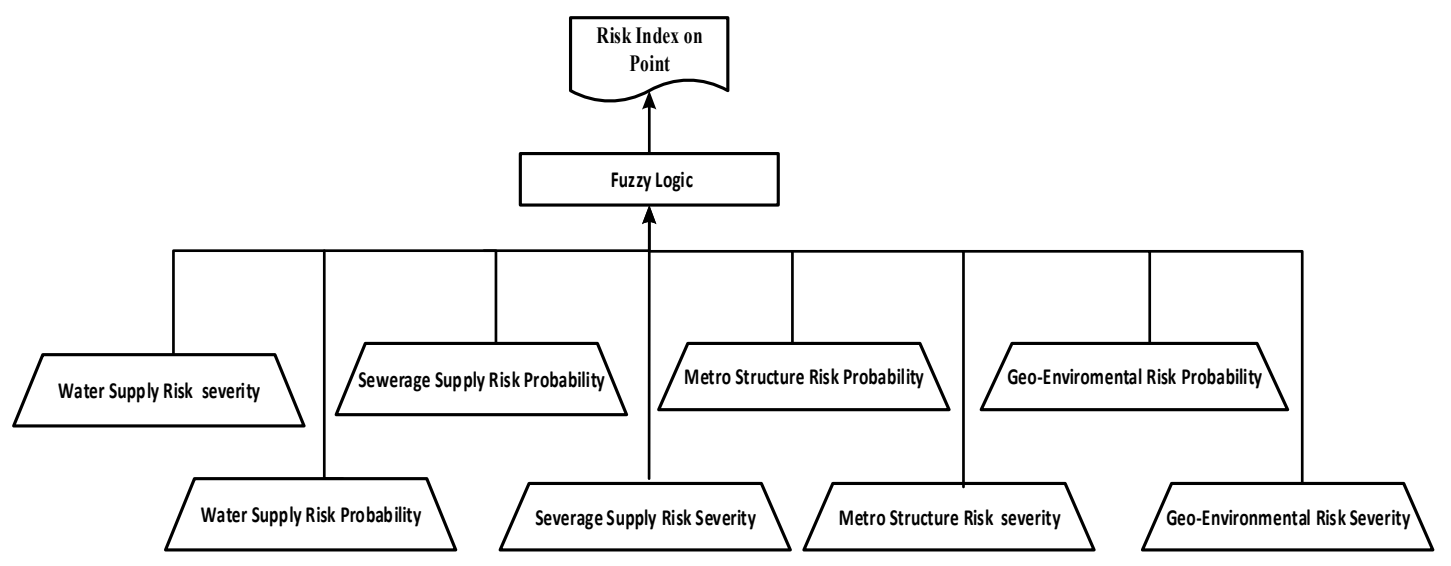

Figure 2. Conventional fuzzy logic with same number of input parameters.

\subsection{Detailed Structure Diagram of the Proposed Model}

The detailed structure diagram given in Figure 3 exhibits the working of each module of the proposed model. The terms used in the detail structure diagram of the proposed approach are: pipeline risk probability $\left(X_{1}\right)$, pipeline risk severity $\left(X_{2}\right)$, sewerage risk probability $\left(X_{3}\right)$, sewerage risk severity $\left(X_{4}\right)$, metro structure risk probability $\left(X_{5}\right)$, metro structure severity $\left(X_{6}\right)$, geo-environmental risk probability $\left(X_{7}\right)$, and geo-environmental risk severity $\left(X_{8}\right)$. BL ( ): represents the blended layer that takes inputs from the input layer. The $\mu\left(x_{i}\right)$ returns fuzzy value, where $i=1,2 \ldots 8$. The $\mu\left(z_{j}\right)$ returns implicated fuzzy value, where $j=1,2 \ldots 25$. The $\mu\left(y_{k}\right)$ returns the final output of fuzzy logic, where $k=1,2,3$, and 4 in the blended layer of the proposed model. Similarly, CL ( ) represents the collaborative layer. The input to the CL ( ) is the output of BL ( ). The $\mu\left(\mathrm{m}_{\mathfrak{j}}\right)$ returns implicated fuzzy value, and $\mu(\mathrm{nr})$ returns the output of fuzzy logic, where $r=1$ and 2 in the collaborative layer. The IL ( ) represents the integrated layer, and $\mu$ (ti) returns the implicated fuzzy value. The $\mu(\mathrm{r})$ returns the output of IR ( ), which is the 
final risk index of the proposed model for underground risk assessment. The $\mathrm{R}$ represents the final risk index value. Agg ( ) return aggregation, arrow symbol " $\leftarrow$ ", has been used for the assignment.

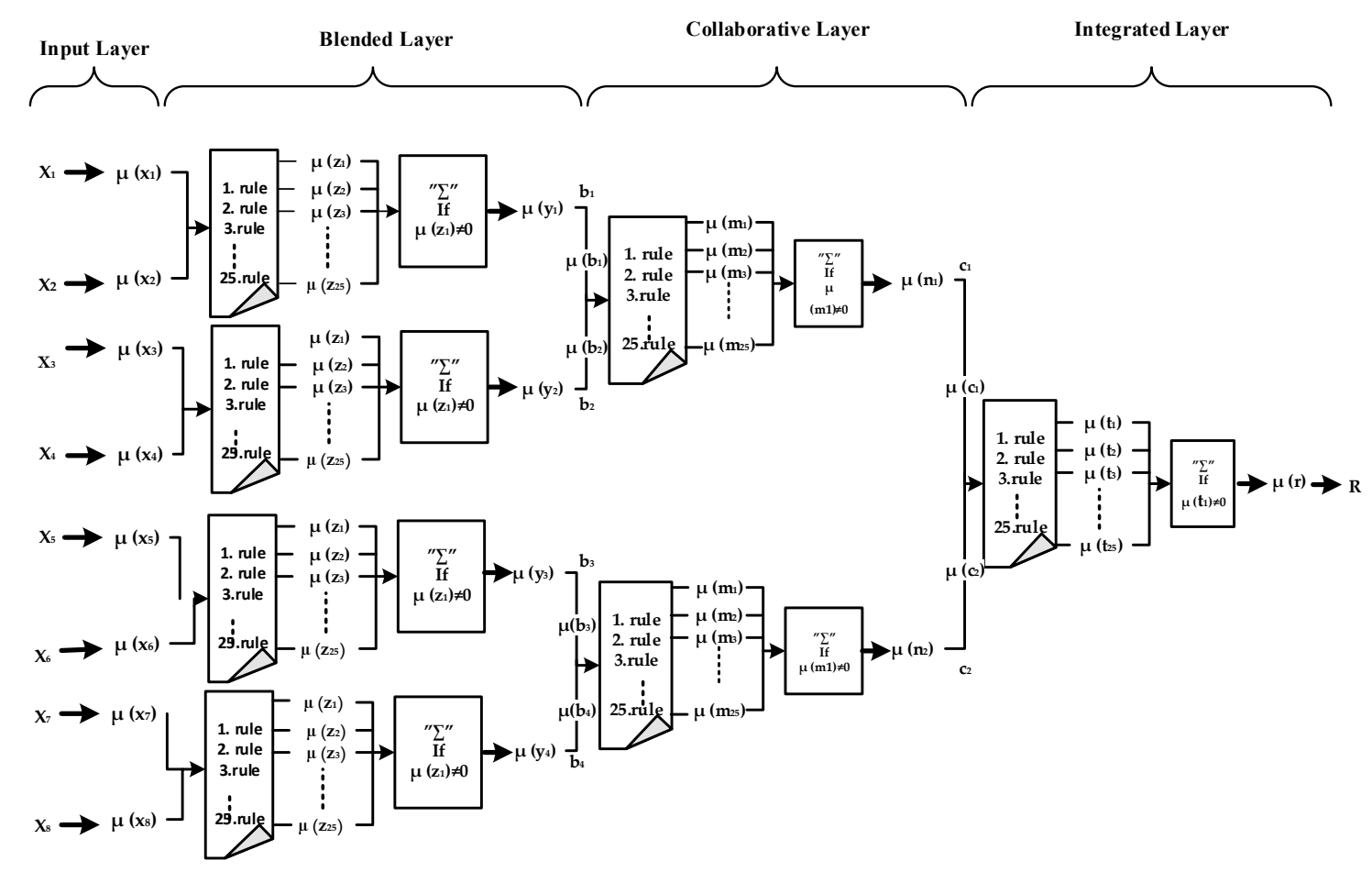

Figure 3. Processing diagram of the proposed integrated risk index model based on hierarchical fuzzy logic.

\subsection{Pseudo Code with Structure Diagram}

The pseudo code with the structure diagram of each layer is provided for better elaboration of the proposed approach in terms of input and output parameters and detailed processing of integrated hierarchal model. The symbols and terminologies are inherited from Section 3.1. The pseudo code with structure diagram for the blended layer is provided in Section 3.2.1, for the collaborative layer in Section 3.2.2 and for the integrated layer in Section 3.2.3.

\subsubsection{Blended Layer}

The blended layer is the most important layer of the proposed model; this layer consists of four modules, namely, water supply risk index fuzzy logic ( $\mathrm{M}_{1} \_$FIS), sewerage supply risk index fuzzy logic ( $\mathrm{M}_{2}$ FIS $)$, metro structure risk index fuzzy logic ( $\mathrm{M}_{3}$ FIS $)$, and Geo-environmental risk index fuzzy (G_FIS) logic. Inputs to the water supply risk index fuzzy logic are water supply risk probability and water supply risk severity, and the output is water supply pipeline risk index; sewerage supply pipeline risk index takes sewerage supply risk index probability and sewerage supply risk severity as inputs and provides sewerage supply risk index as output; metro structure fuzzy logic inputs are metro structure risk probability and metro structure risk severity, and the output is metro structure risk index. Similarly, inputs to Geo-environmental risk index fuzzy logic are Geo-environmental risk index probability and Geo-environmental risk severity, and the output is Geo-environmental risk index. 


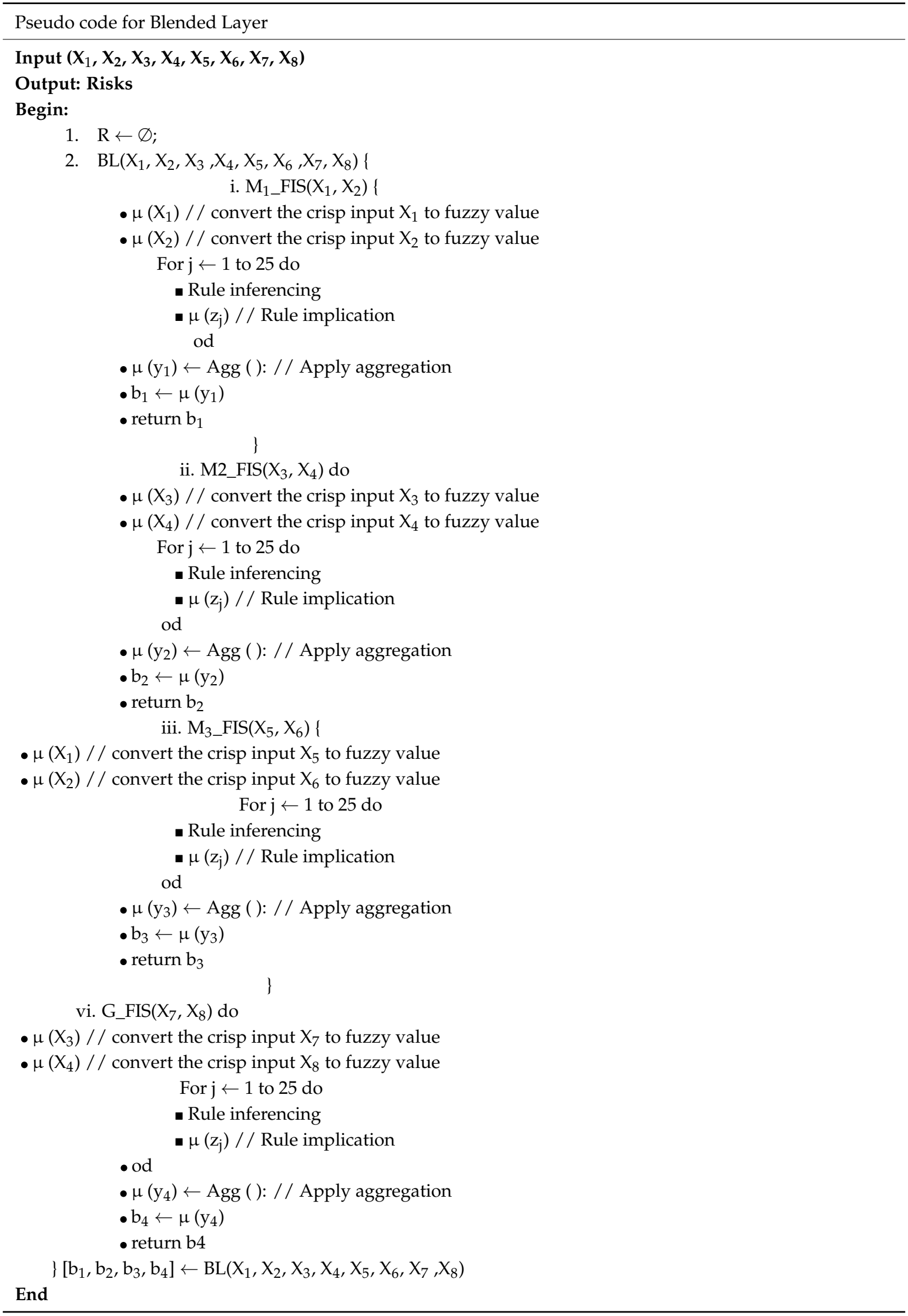

The structure diagram of the blended layer of the proposed model with eight inputs and four outputs is illustrated in Figure 4 for better elaboration of the working mechanism of the blended layer. 


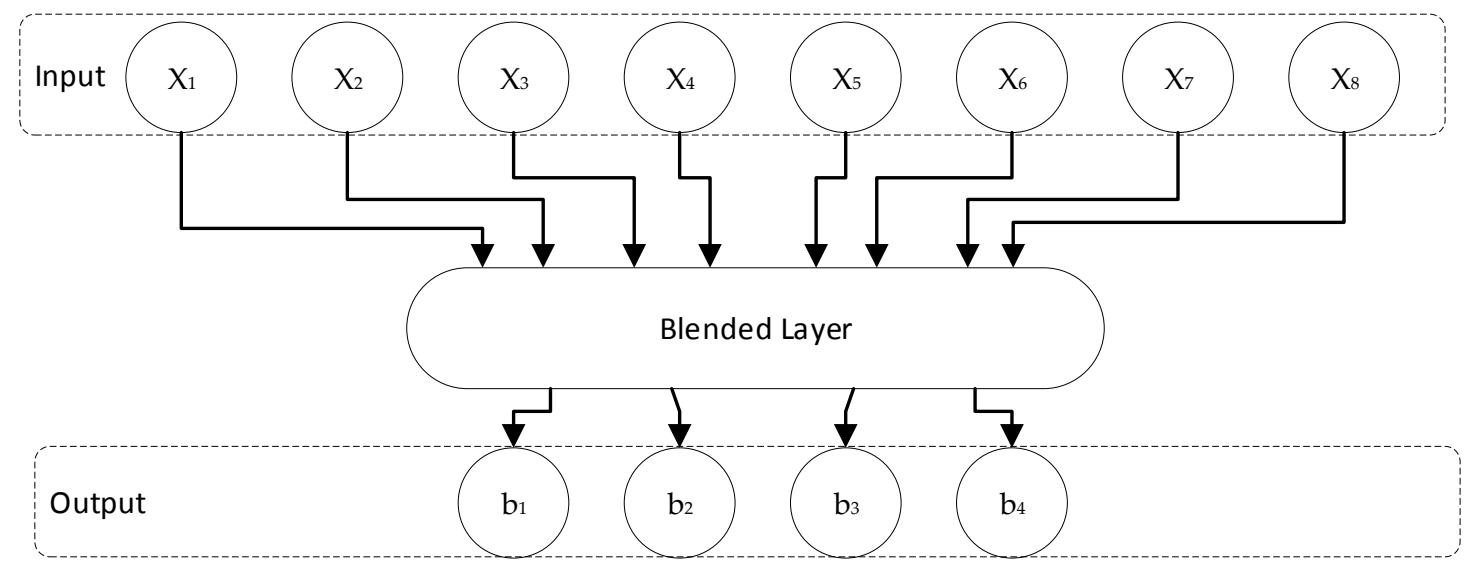

Figure 4. Structure diagram of the blended layer.

\subsubsection{Collaborative Layer}

The collaborative layer of the proposed model is comprised of two modules: namely, collaborative risk index ( $\mathrm{CR}_{1}$ FIS) and collaborative risk index $2\left(\mathrm{CR}_{2}\right.$ FIS). The outputs of the blended layer are inputs to this layer, such as $\mathrm{CR}_{1}$ FIS; inputs are $b_{1}$ and $b_{2}$, which are outputs of $\mathrm{M}_{1 \_}$FIS and $\mathrm{M}_{2}$ FIS respectively and CR2_FIS inputs are $b_{3}$ and $b_{4}$, which are the outputs of $M_{3}$ FIS and G_FIS, respectively.

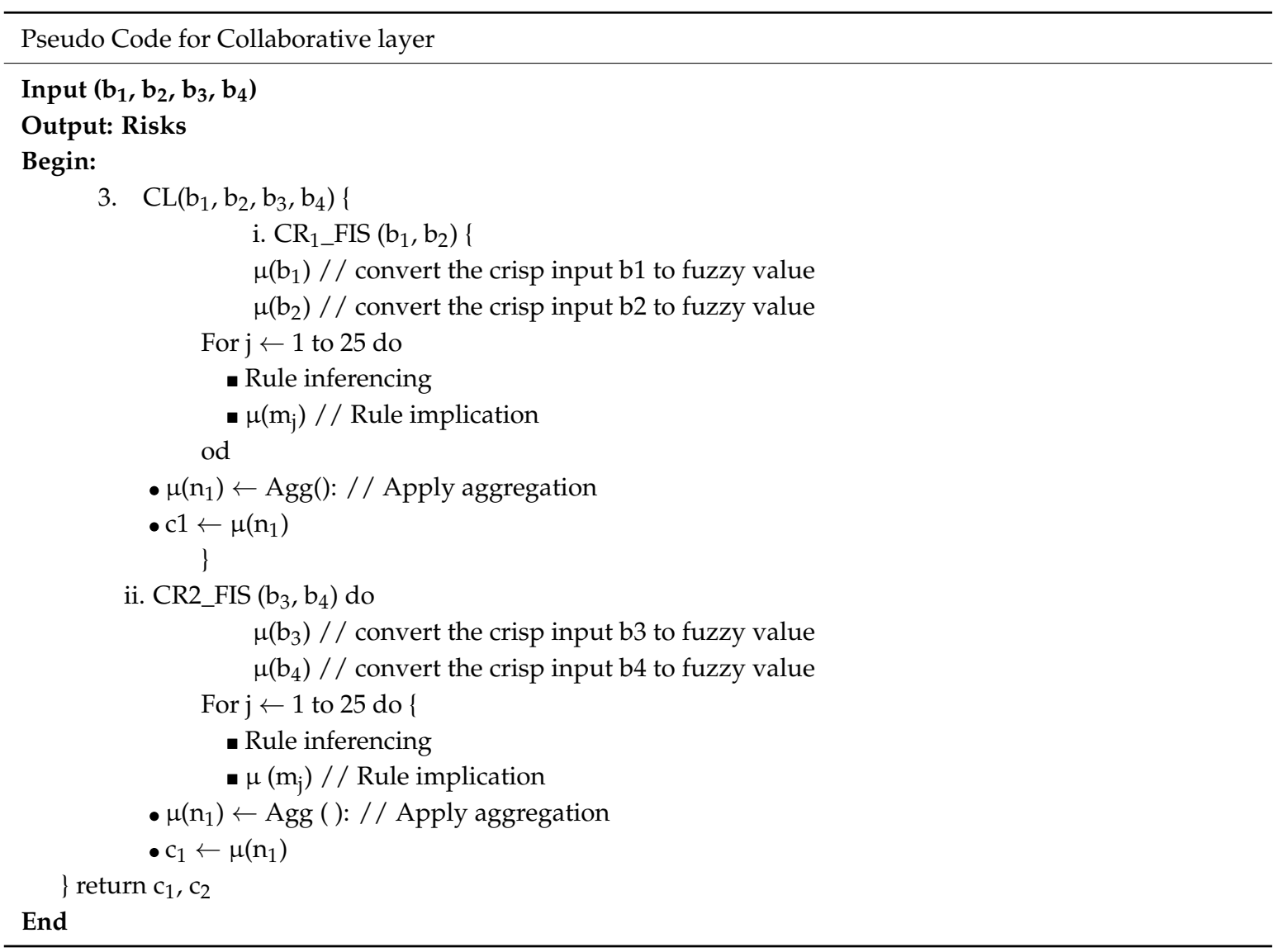

The collaborative layer of the proposed model having four inputs and two outputs is given in Figure 5, which elaborates the working of the collaborative layer of the model. 


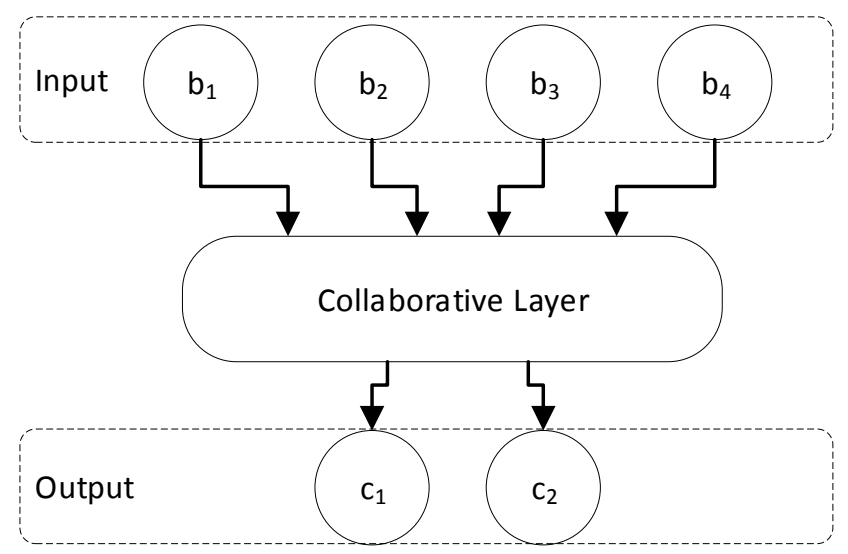

Figure 5. Structure diagram of the collaborative layer.

\subsubsection{Integrated Layer}

The integrated layer consists of one module named integrated fuzzy logic risk index (IR_FIS)). Inputs to integrated layer are the outputs of the collaborative layer. IR_FIS take $\mathrm{CR}_{1}$ and $\mathrm{CR}_{2}$ outputs as inputs and generate index value. The output of the integrated layer is the final output of the proposed model and further measurements are taken on the basis of risk value. The pseudo code of the integrated layer is as under:

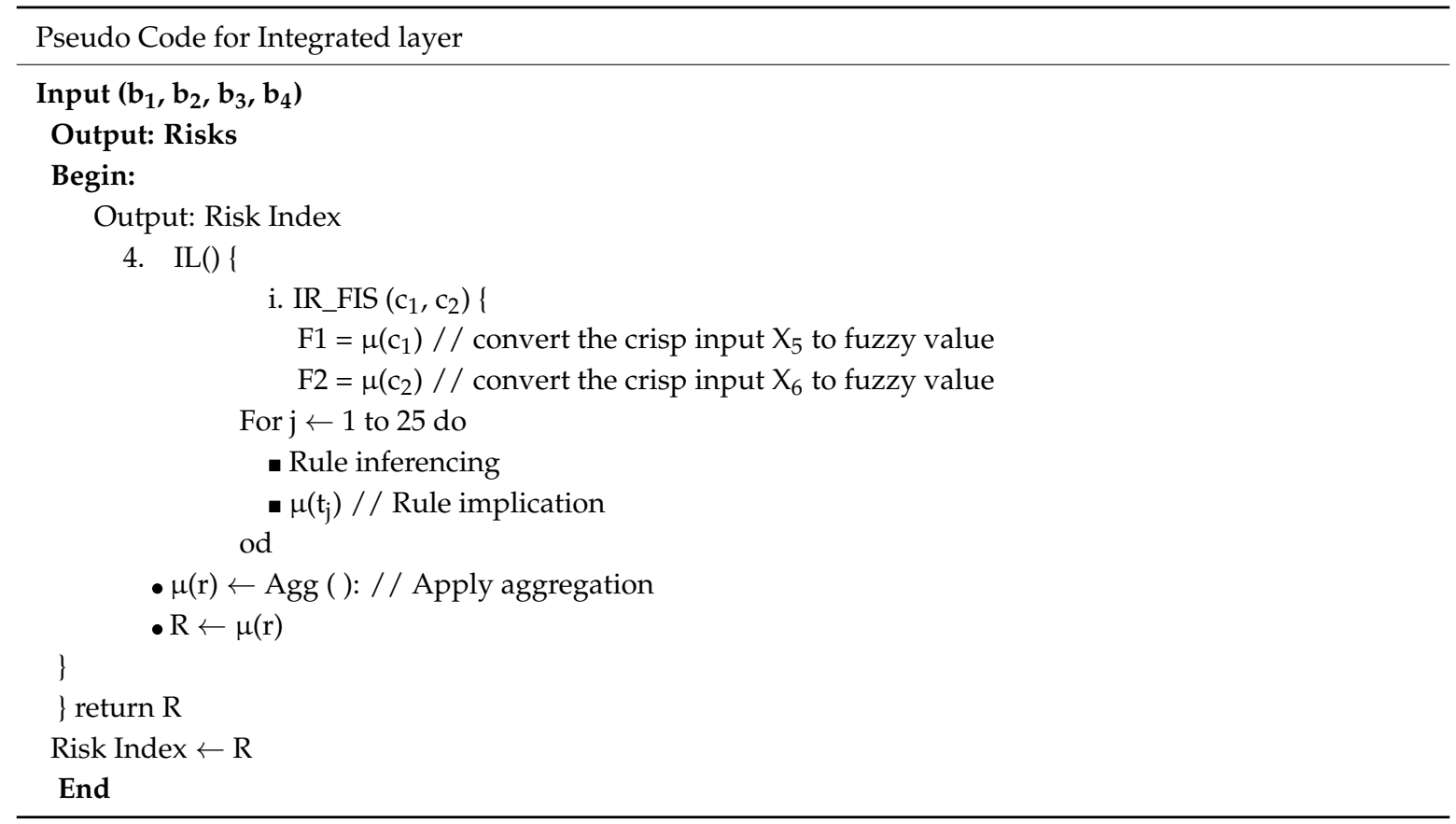

Similarly, for better elaboration of the integrated layer of the proposed model, the structure diagram is illustrated in Figure 6. 


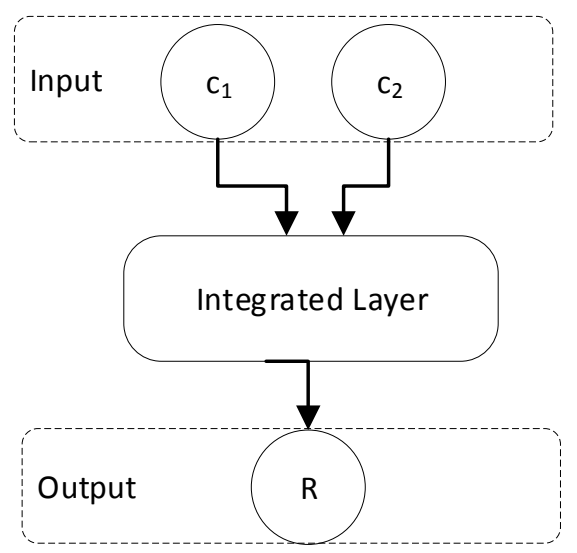

Figure 6. Structure diagram of the integrated layer.

\subsection{Defining Rules in the Proposed Model}

The total number of rules in the proposed hierarchical fuzzy system can be defined using Equation (1).

$$
\text { Number of rules }=\sum_{i=1}^{\mathrm{L}}\left(\mathrm{f}_{i} \times \mathrm{m}^{n_{i}}\right)
$$

In the conventional fuzzy logic the total number of rules can be defined using Equation (2).

$$
\text { Number of rules }=\mathrm{m}^{n}
$$

where $\mathrm{L}$ is the number of levels (input layer is not considered), $\mathrm{m}$ is the number of membership functions, $n$ is the number of input variables in fuzzy logic and $f$ is the number of fuzzy logics in each level. In the proposed system, each fuzzy logic has two inputs so the value of $n$ is equal to 2 . In conventional fuzzy logic, all eight inputs go directly into the single fuzzy logic so $n$ is 8 .

\subsection{Rule Specification}

For the rule specification, we have designed two different schemes: namely, average rule-based and maximum rule-based. In the average rule-based, first the weights are assigned to each membership function (MF), as shown in the Table 1.

Table 1. Membership functions linguistic terms with weights.

\begin{tabular}{cccccc}
\hline Linguistic Terms & VL & L & M & H & VH \\
\hline Numeric Value & 1 & 2 & 3 & 4 & 5 \\
\hline
\end{tabular}

VL: very low; L: low; M: medium; H: high; VH: very high.

The formulas for specifying average rule-based and maximum rule-based rules are given in Equations (3) and (4), respectively.

$$
\begin{aligned}
\operatorname{Avg} & =(\mathrm{MF}+\mathrm{MF}) / 2 \\
\operatorname{Max} & =\max (\mathrm{MF}, \mathrm{MF})
\end{aligned}
$$

For the rule specification using the average rule-based method, first the weights of membership functions are put in the Equation (3) and the output of rules are specified accordingly. Each output of the rule is specified as:

$$
\begin{aligned}
& \operatorname{Avg}=(\mathrm{VL}+\mathrm{L}) / 2=(1+2) / 2=1.5=2=\mathrm{L} \\
& \operatorname{Avg}=(\mathrm{VL}+\mathrm{H}) / 2=(1+4) / 2=2.5=3=\mathrm{M}
\end{aligned}
$$




$$
\begin{aligned}
& \operatorname{Avg}=(\mathrm{L}+\mathrm{M}) / 2=(2+3) / 2=2.5=3=\mathrm{M} \\
& \operatorname{Avg}=(\mathrm{M}+\mathrm{H}) / 2=(3+4) / 2=3.5=4=\mathrm{H}
\end{aligned}
$$

Table 2 indicates the fuzzy logic rules on the average rule-based method for $\mathrm{M}_{1 \_}$FIS. It is a $5 \times 5$ matrix and each entry in Table 2 is the water supply pipeline risk index.

\begin{tabular}{|c|c|c|c|c|c|}
\hline $\mathrm{X}_{2} \mathrm{X}_{1}$ & VL & L & $\mathbf{M}$ & H & VH \\
\hline VL & VL & VL & L & $\mathrm{M}$ & M \\
\hline $\mathbf{L}$ & VL & $\mathrm{L}$ & $\mathrm{M}$ & $\mathrm{M}$ & $\mathrm{H}$ \\
\hline $\mathbf{M}$ & $\mathrm{L}$ & M & $\mathrm{M}$ & $\mathrm{H}$ & $\mathrm{VH}$ \\
\hline $\mathbf{H}$ & $\mathrm{M}$ & M & $\mathrm{H}$ & VH & $\mathrm{VH}$ \\
\hline VH & $\mathrm{M}$ & $\mathrm{H}$ & VH & VH & $\mathrm{VH}$ \\
\hline
\end{tabular}

Table 2. Average rule-based mechanism for water supply pipeline risk index fuzzy logic.

For the rule specification by using the maximum rule-based method, first the membership function weights are put in the Equation (3), and the output of rules specification is carried out accordingly. The output of each rule is specified as:

$$
\begin{gathered}
\operatorname{Max}=\max (\mathrm{VL}, \mathrm{L})=\max (1,2)=2 \\
\operatorname{Max}=\max (\mathrm{L}, \mathrm{M})=\max (2,3)=3 \\
\operatorname{Max}=\max (\mathrm{VL}, \mathrm{H})=\max (1,4)=4 \\
\operatorname{Max}=\max (\mathrm{L}, \mathrm{M})=\max (2,3)=3
\end{gathered}
$$

\begin{tabular}{|c|c|c|c|c|c|}
\hline$X_{1}$ & VL & L & $\mathbf{M}$ & H & VH \\
\hline VL & VL & L & $\mathrm{M}$ & $\mathrm{H}$ & $\mathrm{VH}$ \\
\hline $\mathbf{L}$ & $\mathrm{L}$ & L & $\mathrm{M}$ & $\mathrm{H}$ & $\mathrm{VH}$ \\
\hline $\mathbf{M}$ & $\mathrm{M}$ & $\mathrm{M}$ & $\mathrm{M}$ & $\mathrm{H}$ & $\mathrm{VH}$ \\
\hline $\mathbf{H}$ & $\mathrm{H}$ & $\mathrm{H}$ & $\mathrm{H}$ & $\mathrm{H}$ & $\mathrm{VH}$ \\
\hline VH & $\mathrm{M}$ & $\mathrm{VH}$ & $\mathrm{VH}$ & VH & $\mathrm{VH}$ \\
\hline
\end{tabular}

Table 3 indicates the fuzzy logic rules based on the maximum rule-based method for water supply pipeline risk index fuzzy logic. It is a $5 \times 5$ matrix and each entry in Table 3 is the water supply pipeline risk index.

Table 3. Maximum rule-based mechanism for water supply pipeline risk index fuzzy logic.

\section{Experimental Results and Discussion}

\subsection{Experimental Setup}

For experimental analysis of our proposed model, we have used Matlab installed on Intel(R) core (TM) i5-3570 CPU@3.40 GHz computer system. Every input feature is rated on a standard 0-10 scale, and we have defined five membership functions for each variable. First, we have defined membership functions for each input variable in the blended layer. The blended layer has four constituent fuzzy components i.e., $\mathrm{M}_{1}$ FIS, $\mathrm{M}_{2}$ FIS, $\mathrm{M}_{3}$ FIS, and G_FIS. Figure 7 shows the membership functions for input and output variables of M1_FIS, which deals with water supply risk index. This fuzzy logic has two input variables and one output variable. For brevity, we use the terms VL, L, M, H, and VH for membership functions, abbreviated from very low, low, medium, high, and very high, respectively. 


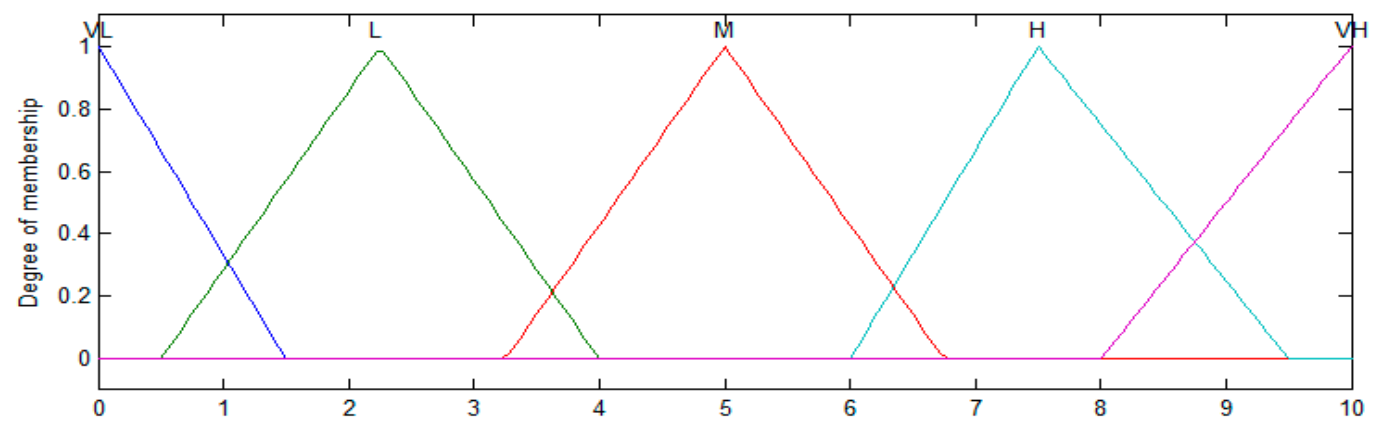

(a)

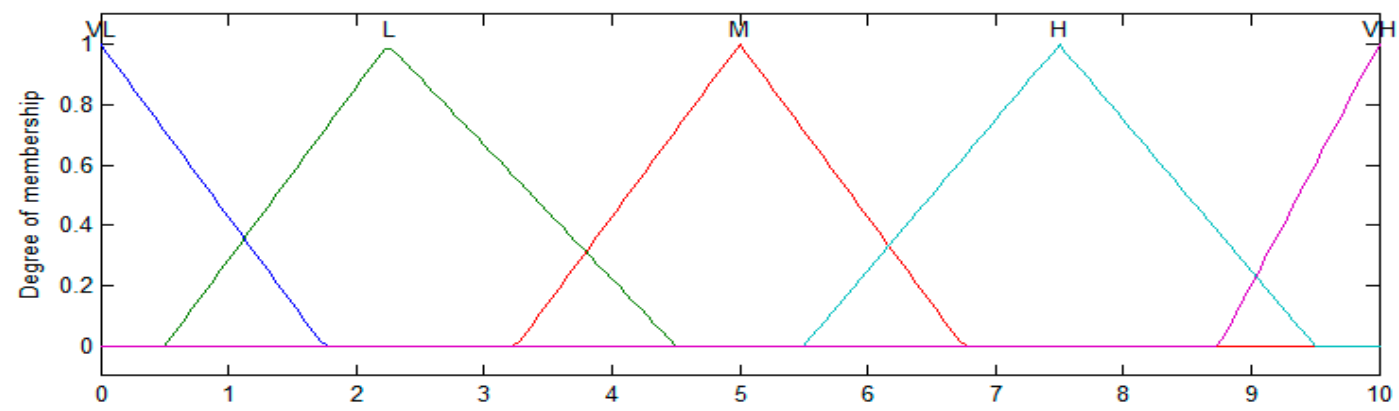

(b)

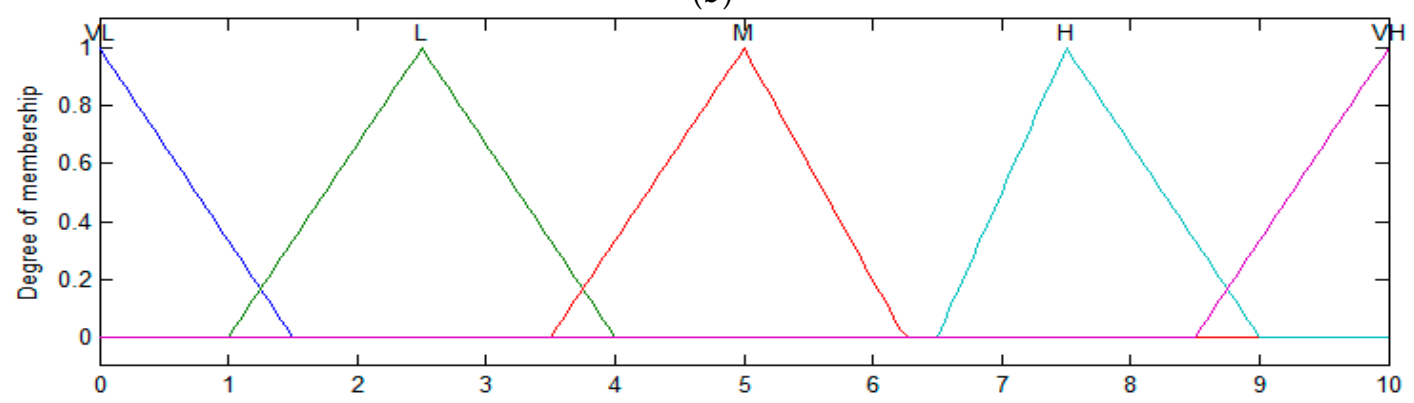

(c)

Figure 7. Input/output membership functions: (a) water supply risk probably; (b) water supply risk severity; and (c) water supply risk index.

Similarly, we have defined membership functions for all other constituent fuzzy components of blended layer, i.e., $\mathrm{M}_{2}$ FIS, $\mathrm{M}_{3}$ FIS, and G_FIS, to handle sewerage supply, metro structure, and geo-environmental risk factors. Accordingly, we defined membership function for fuzzy components in the collaborative layer. For fuzzy logic in the integrated layer, membership functions for input/output variables are defined in Figure 8, where $C_{1}$ and $C_{2}$ are the input variables and IR is the output variable of IR_FIS.

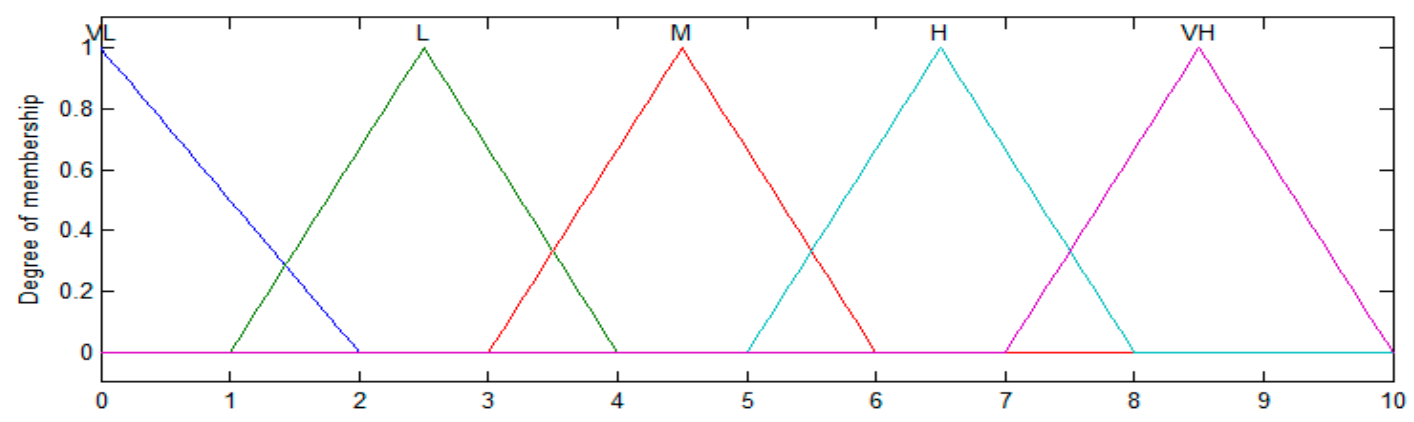

(a)

Figure 8. Cont. 


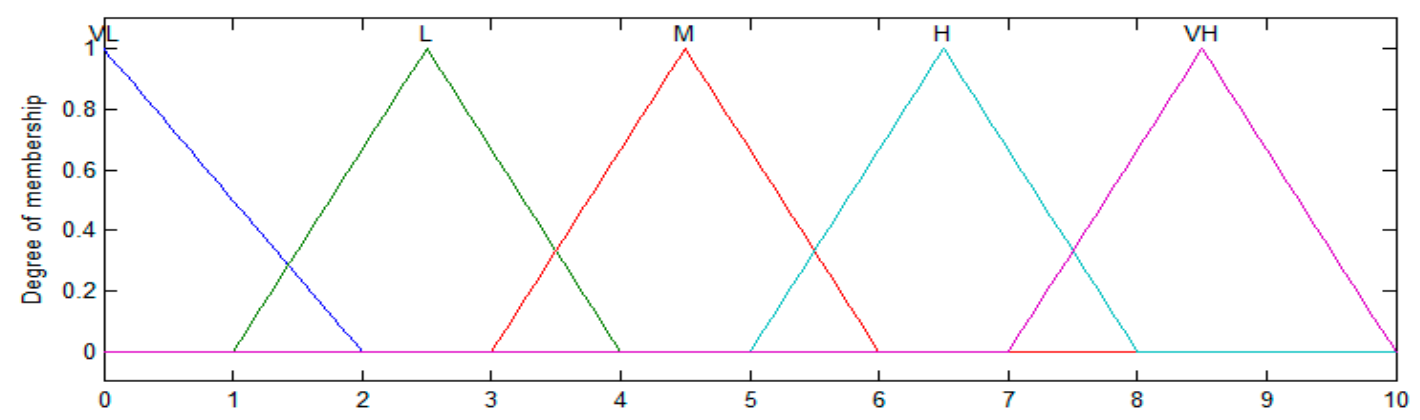

(b)

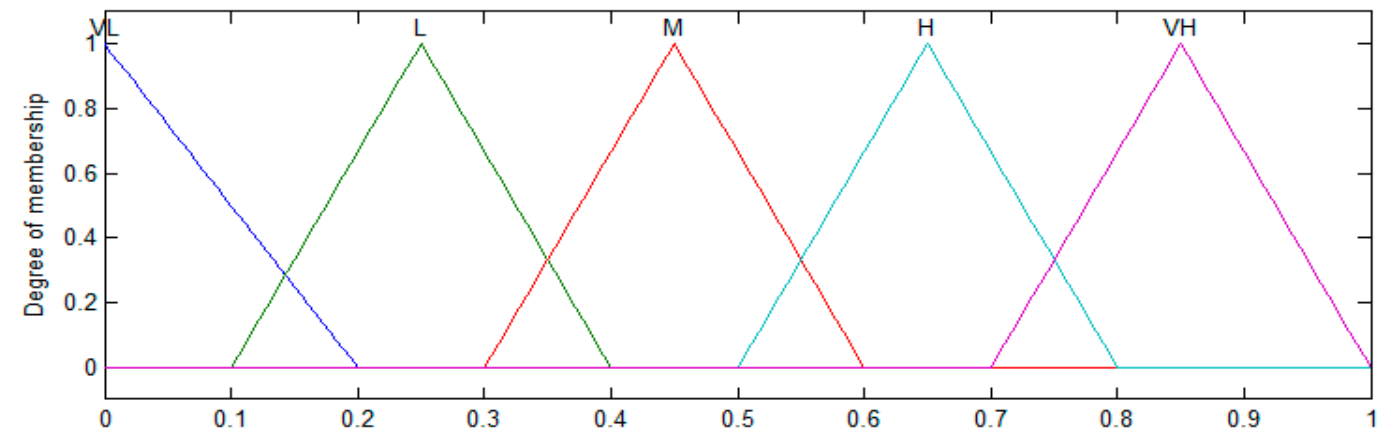

(c)

Figure 8. Input/output membership functions for (a) collaborative risk index 1; (b) collaborative risk index 2; and (c) integrated risk index.

The rule editor in Matlab fuzzy logic toolbox provides the facility for rule specification. The rules given in Table 2, which are calculated using the average rule-based method, are specified using rule editor, as shown in Figure 9.

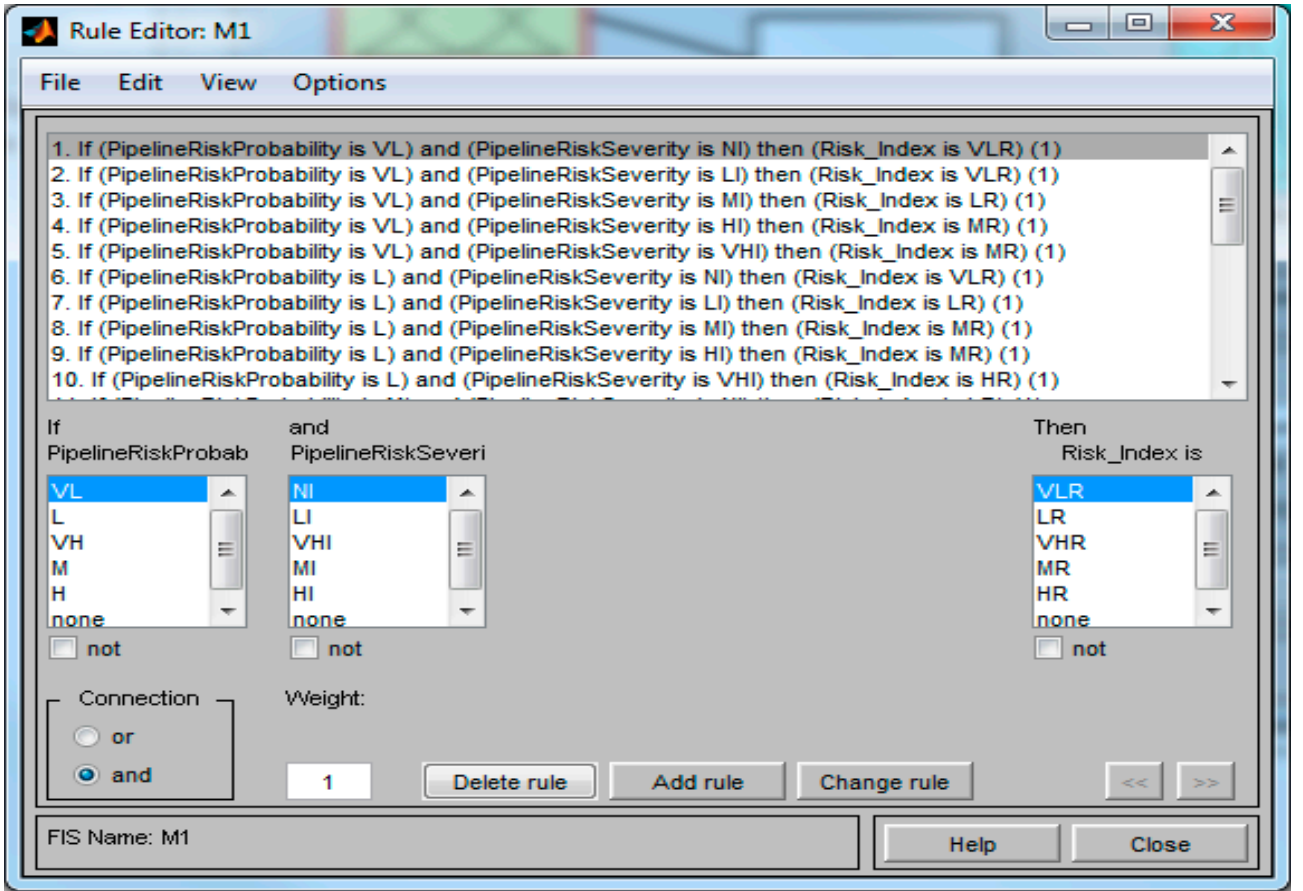

Figure 9. Rule editor for specifying average rule-based method rules. 
In the same way, the rules have been defined for fuzzy logic in the blended layer and collaborative layer using the average rule-based method. For the output rules specification of the fuzzy logic of integrated layer, both maximum rule-based and average rule-based mechanisms are used. The rules given in Table 3, which are calculated using maximum rule-based method, are specified using rule editor, as shown in Figure 10.

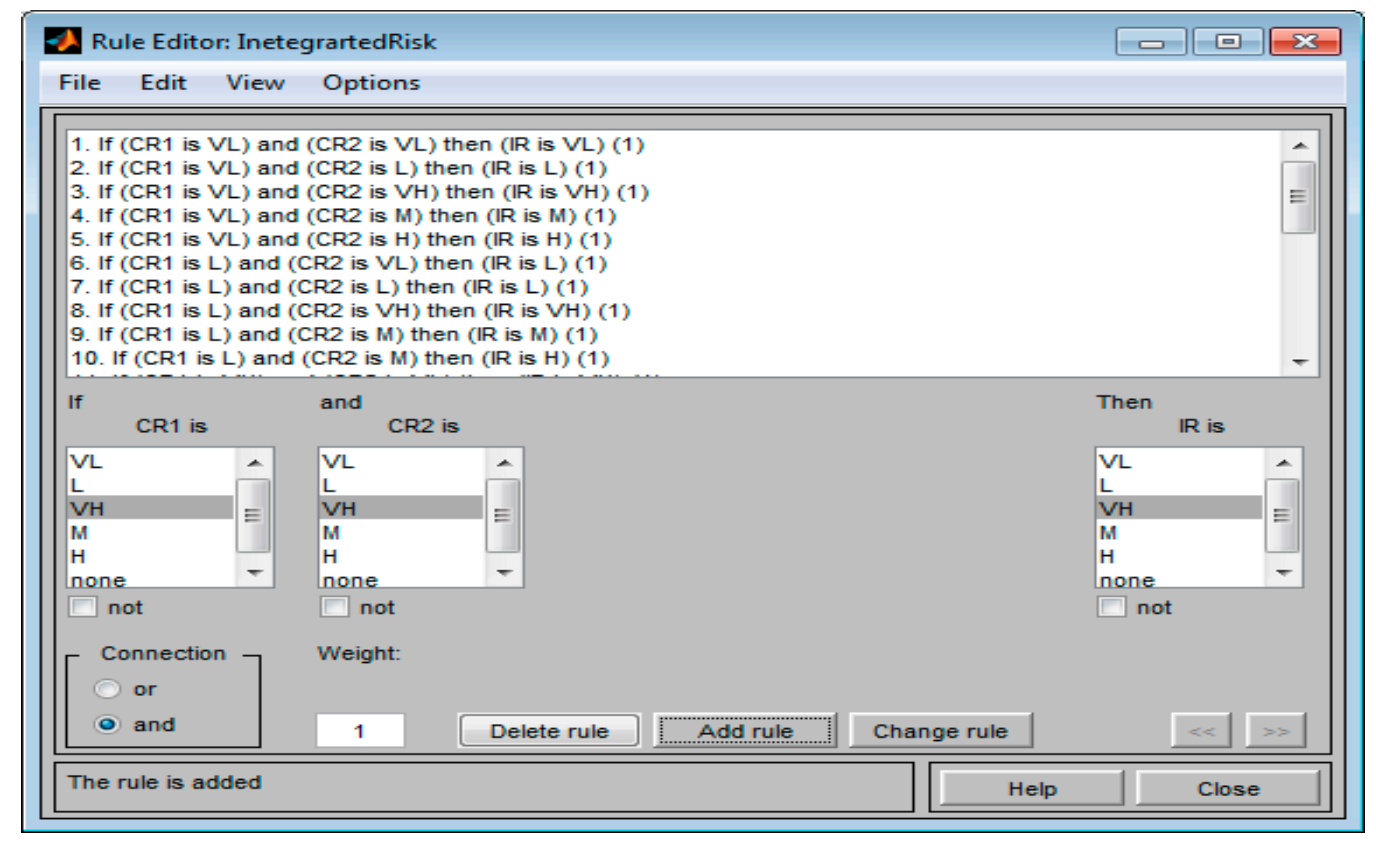

Figure 10. Rule editor for specifying maximum rule-based methods rules.

\subsection{Results}

The data was generated by using exponential equations for the simulation of the proposed model. The exponential data was generated in increasing order in different ways for 1000 instances from 0.0 to 10.0 with an exponential increase, as illustrated in Figure 11. As there are eight inputs in the proposed hierarchical fuzzy model, the generated four parameters are input to the proposed model in different ways. The purpose of this data generation is to test the working mechanism of the proposed hierarchal fuzzy inference system. The following functions are used for input data generation.

$$
\begin{gathered}
f_{E X_{1}}=10 \times\left(1-e^{\frac{-0.5 x}{200}}\right) \\
f_{E X_{2}}=\frac{e^{0.0092 x}}{1000} \\
f_{E X_{3}}=10 \times\left(1-e^{\frac{-1.5 x}{200}}\right) \\
f_{E X_{4}}=\frac{x^{2}}{100000}
\end{gathered}
$$

The experimental results shown in Figure 12 represent water supply risk index fuzzy logic outputs risk, sewerage supply risk index outputs fuzzy logic, metro structure risk index fuzzy logic outputs, and Geo-environmental risk index outputs in the blended layer of the proposed model. We have applied the average rule-based mechanism in each fuzzy logic of this layer. 


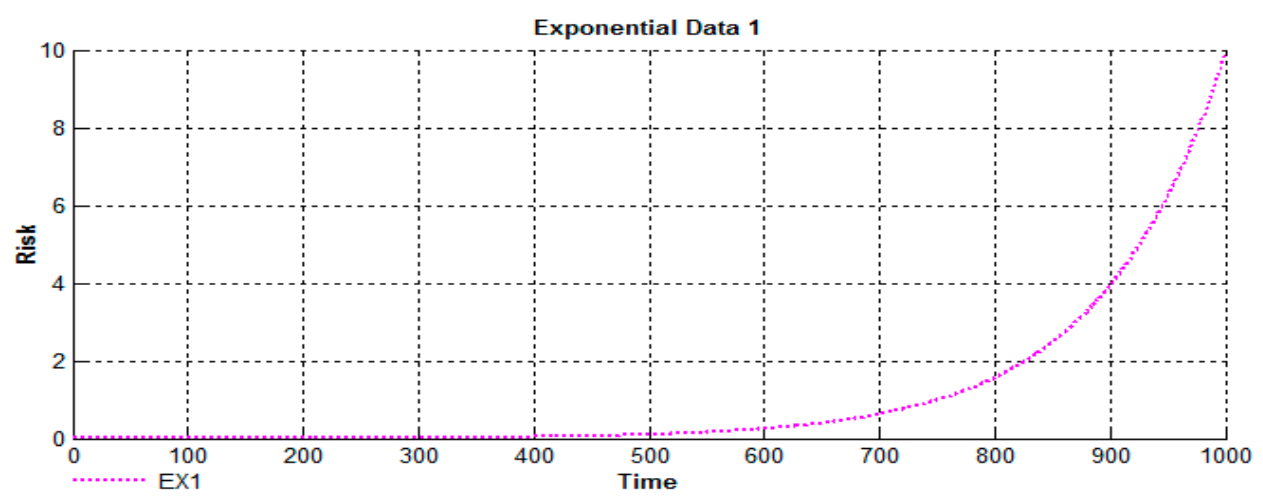

(a)

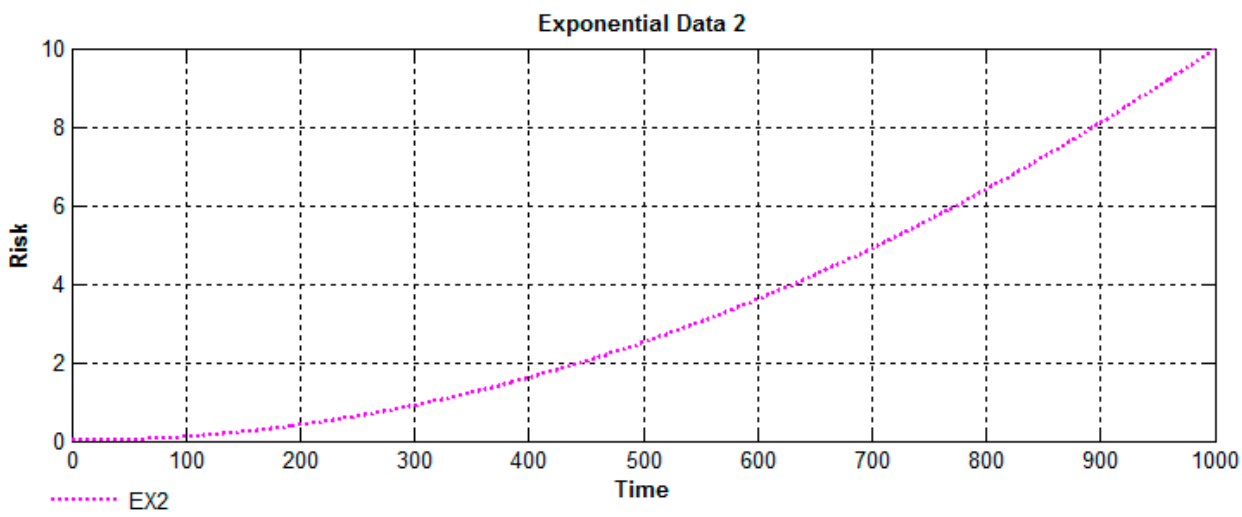

(b)

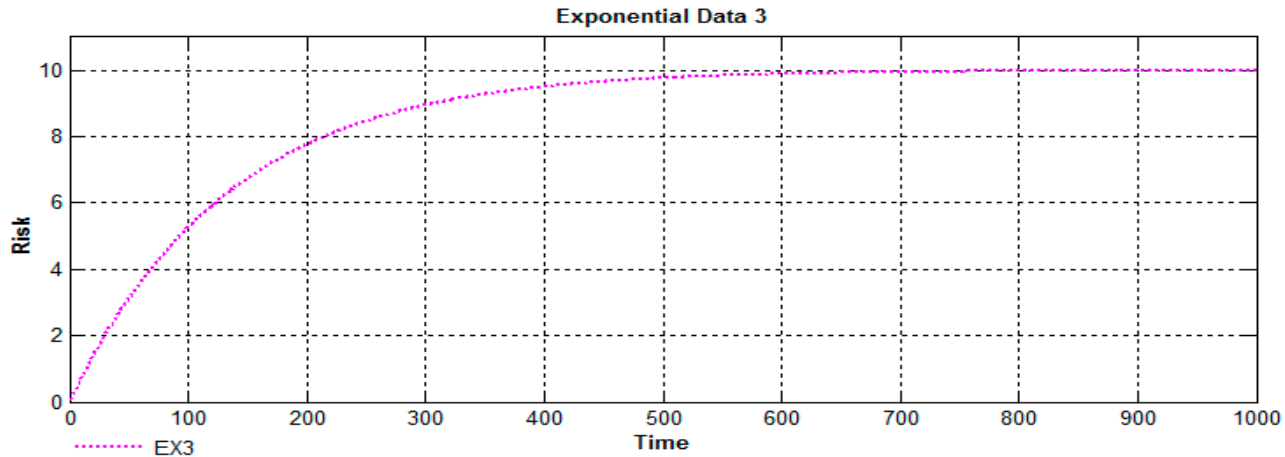

(c)

Exponential Data 4

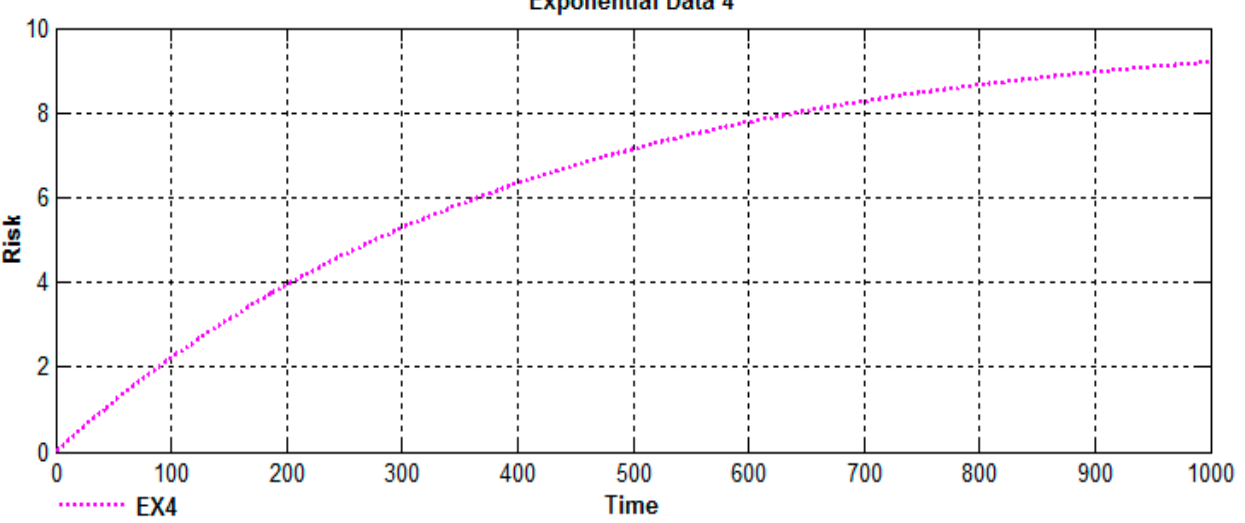

(d)

Figure 11. (a-c) and (d) represent input data generated by using different exponential equations. 


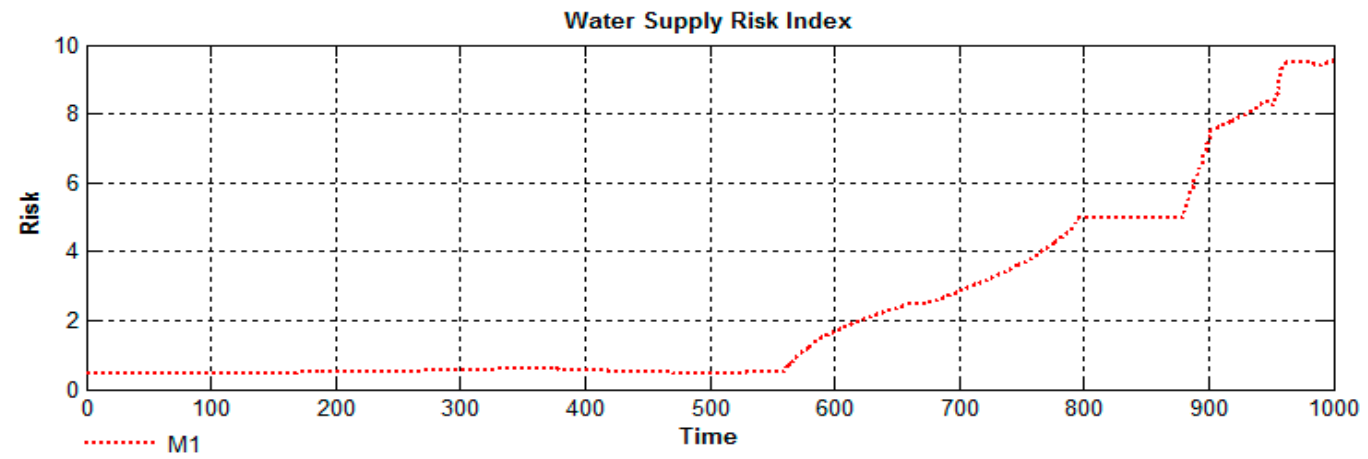

(a)

Sewerae Supply Risk Index

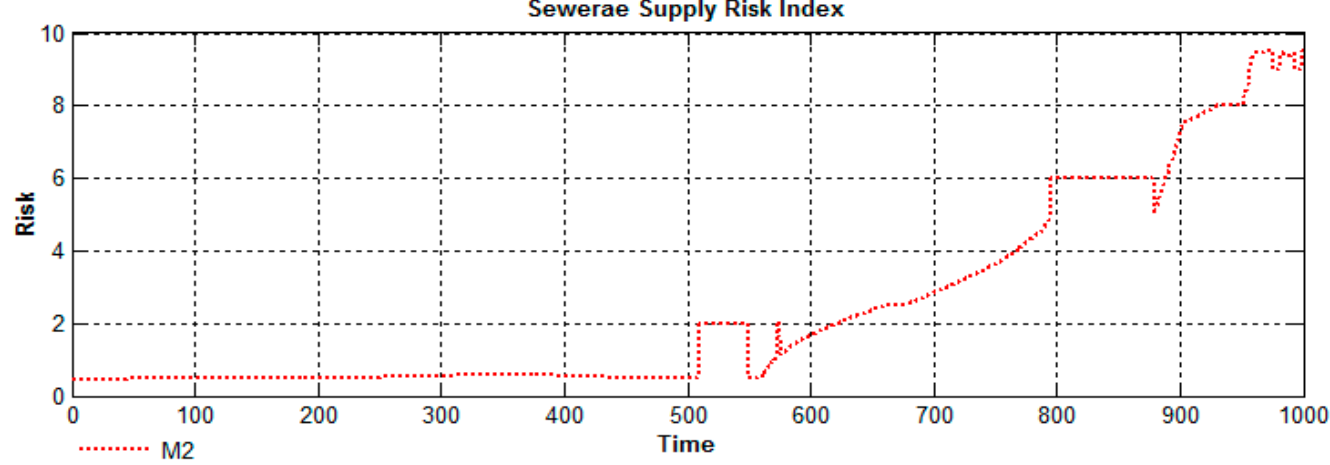

(b)

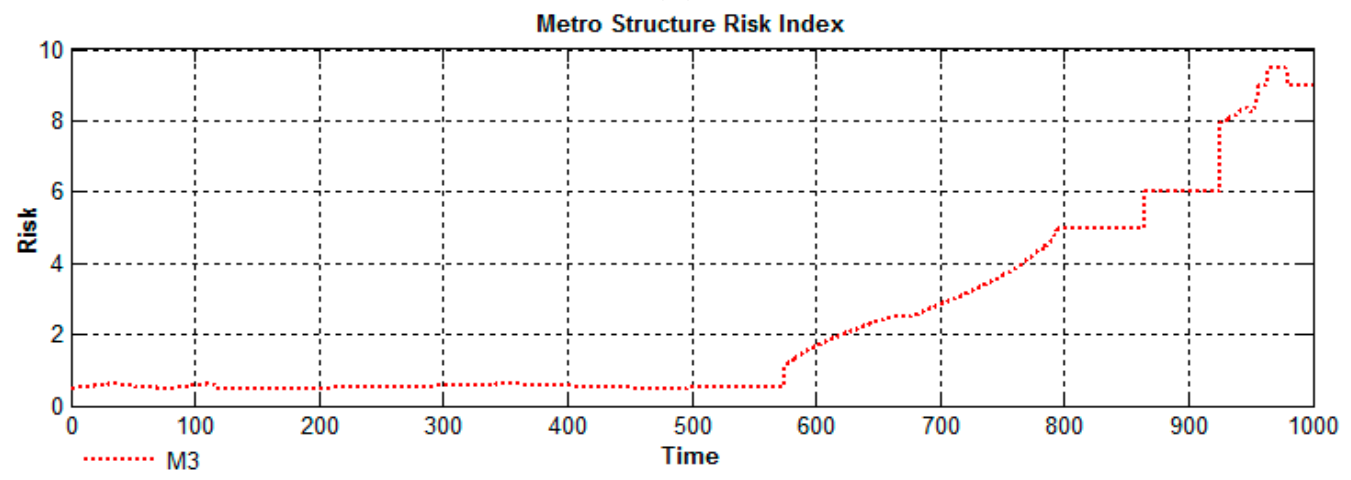

(c)

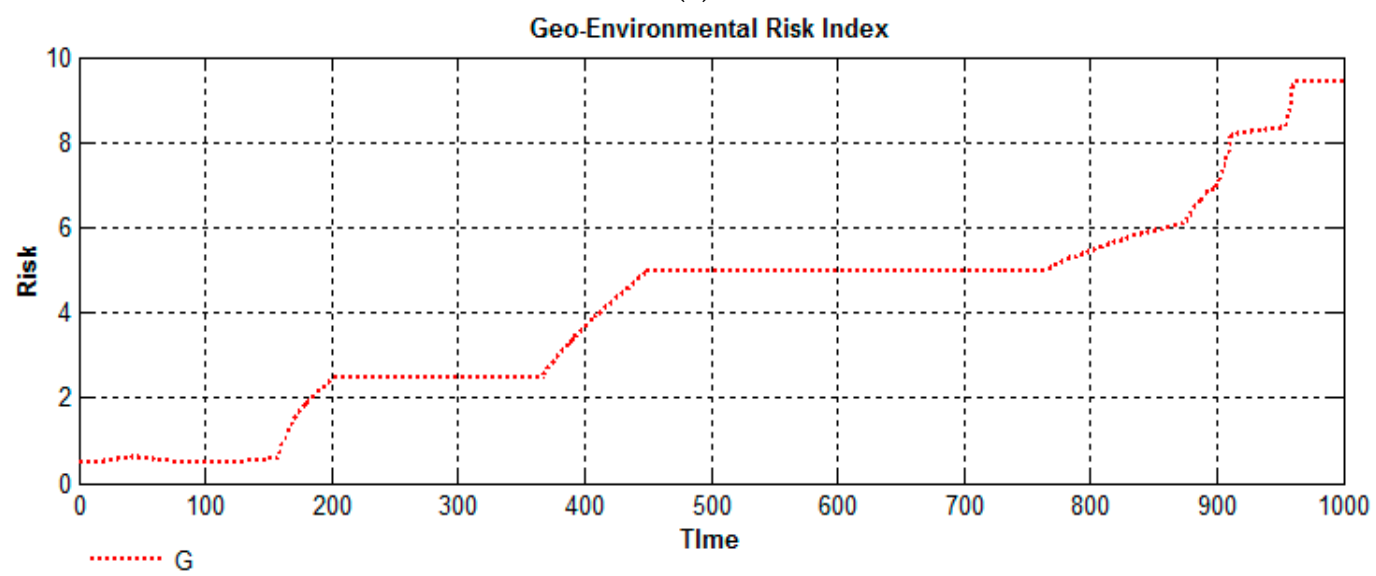

(d)

Figure 12. $(\mathbf{a}-\mathbf{c})$ and $(\mathbf{d})$ are output risk index of fuzzy logics in blended layer. 
The collaborative layer has two fuzzy components, i.e., $\mathrm{CR}_{1}$ and $\mathrm{CR}_{2}$. The average rule-based mechanism has been applied for these two fuzzy logics. The output of $\mathrm{M}_{1}$ and $\mathrm{M}_{2}$ fuzzy logics from the blended layer is given as inputs to $\mathrm{CR}_{1}$ fuzzy logic. Similarly, outputs of $\mathrm{M}_{3}$ and $\mathrm{G}$ fuzzy logic are inputs to $\mathrm{CR}_{2}$ fuzzy logic. Figure 13 shows the output of collaborative layer fuzzy components, i.e., collaborative risk 1 and collaborative risk 2 .

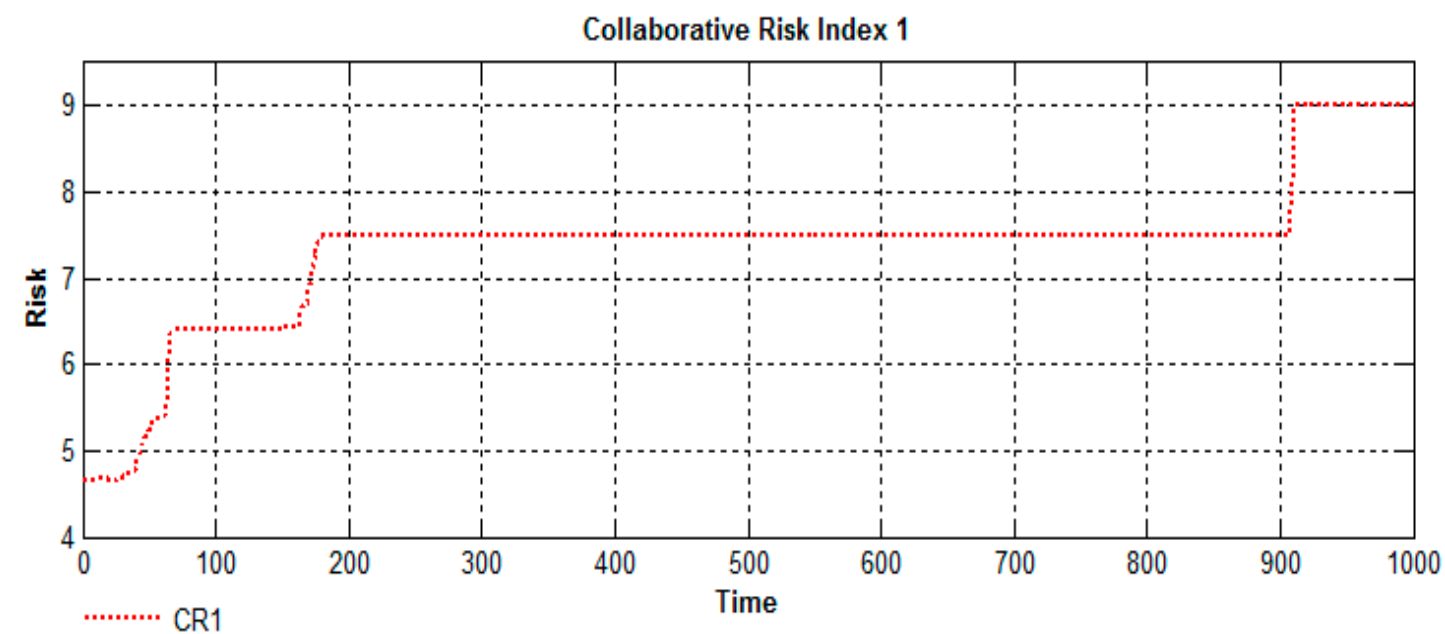

(a)

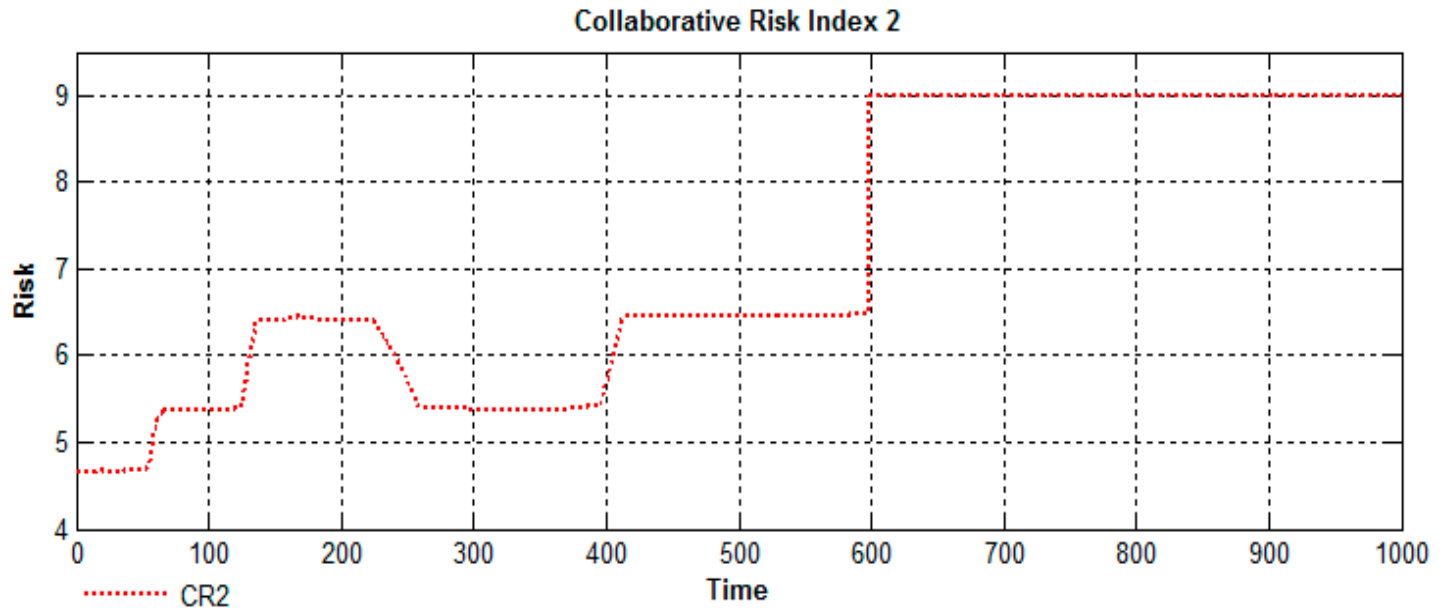

(b)

Figure 13. $(\mathbf{a}, \mathbf{b})$ are output of collaborative risk index fuzzy logics in collaborative layer.

The final output of proposed integrated fuzzy logics has been depicted in Figure 14, wherein the average rule-based and maximum rule-based mechanisms have been applied for specifying rules in for the integrated fuzzy logic. Here in this section, we have used both rule specification mechanisms for the sake of exposing the representation usage of these rules mechanisms. These rule specification methods are introduced in this work in order to assist the manager for specifying rules according to the need of the system. 


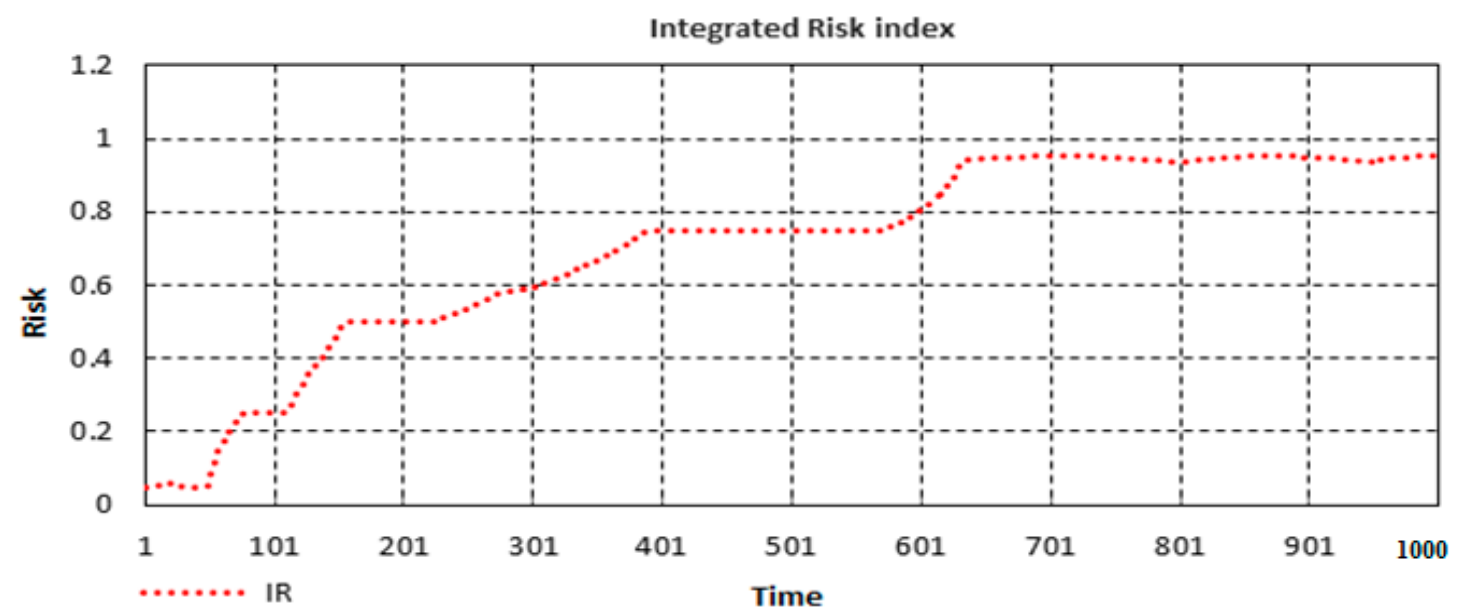

(a)

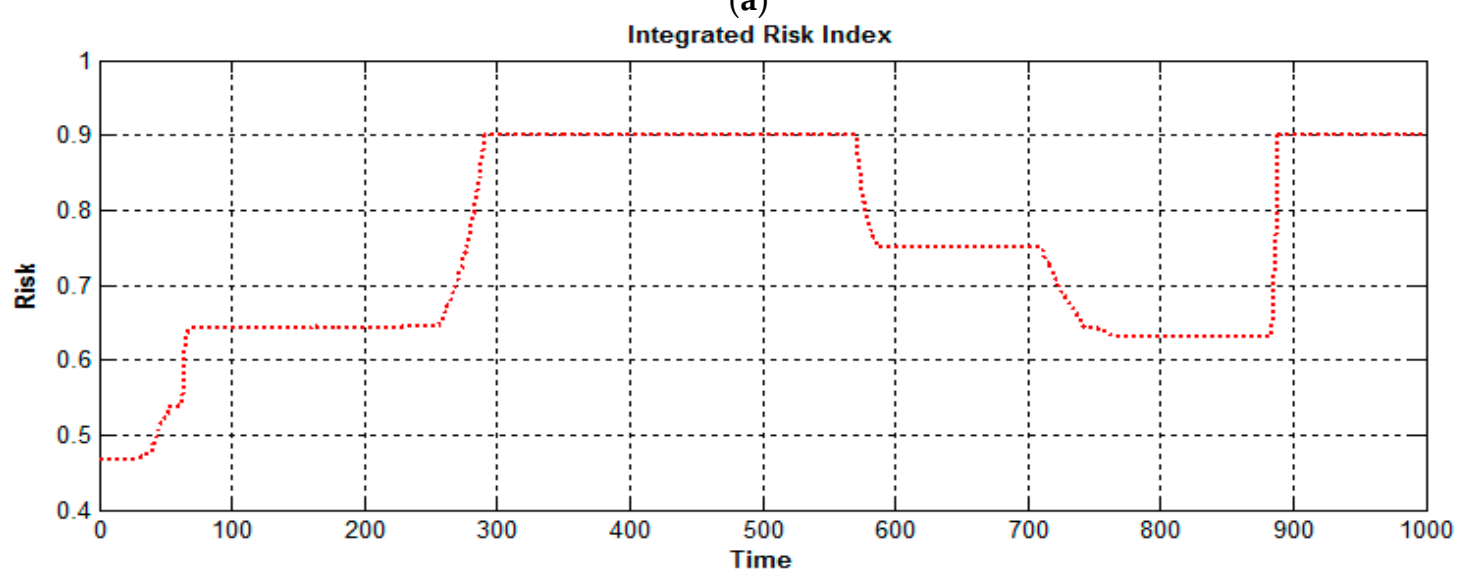

(b)

Figure 14. Output of fuzzy logic for (a) maximum rule-based; and (b) average rule-based rules in integrated layer.

\subsection{Discussion}

Underground risk assessment is very complex due to several parameters. In order to accurately assess the risk of a location, the maximum number of parameters should be taken into account. In the proposed work, eight parameters have been considered for underground risk assessment. The conventional fuzzy logic is not a good choice for the underground risk assessment. The appropriate fuzzy system is required to deal with the curse of dimensionality. The basic objective of the hierarchical fuzzy inference system is to address the major problem particular to fuzzy systems standard multiple variables which is actually the exponential progress in the number of rules based on the number of variables entered in the system, which leads to an impractical problem for the purposes of its implementation for the dimension of the basic rules. Intelligent architecture designing for the hierarchical fuzzy system is a challenging task.

The proposed hierarchical model has various advantages over the conventional fuzzy logic. In the following text, we highlight the major plus points of our proposed hierarchical model.

\subsubsection{Rule Reduction}

The proposed hierarchical fuzzy inference architecture reduces the total number of rules from the rule base. In the proposed method total five membership functions have been defined for each variable. Total of eight input variables have been used; if we put the number of input variables and the 
number of membership functions in Equation (1) for the hierarchical fuzzy logic in (2) for conventional fuzzy logic, the resultant output will be:

$$
\begin{aligned}
& \text { Number of rules for hierarchical fuzzy model }=\sum_{\mathrm{i}=1}^{\mathrm{L}}\left(\mathrm{f}_{i} \times \mathrm{m}^{n_{i}}\right)=\sum_{\mathrm{i}=1}^{3}\left(\mathrm{f}_{i} \times \mathrm{m}^{n_{i}}\right) \\
& =4 \times 52+2 \times 52+1 \times 52=100+50+25=175 \\
& \text { Number of rules for conventional fuzzy logic }=\mathrm{m}^{\mathrm{n}}=5^{8}=390,625
\end{aligned}
$$

Compared to the conventional fuzzy logic, the proposed hierarchical fuzzy architecture significantly reduced the number of rules. Rule reduction is important because the curse of dimensionality damaged the transparency and interpretation as it is very tough to understand and justify hundreds or thousands of fuzzy rules. As a consequence of the curse of dimensionality often rules are overfitted which damages the generalizability of fuzzy systems. Similarly, for an enormous number of rules large storage and fast computation power is required. The total number in fuzzy rule base has a direct influence on fuzzy logic performance. For the underground risk assessment, usually large number of parameters is required to be taken into account, hence the conventional architecture reveals a limitation in the form of real-time performance. Rule reduction is also very important because experts can specify fewer rules with more concentration. To deal with the problem of the curse of dimensionality, this hierarchical fuzzy model is proposed.

\subsubsection{Parameter Reduction}

The main problem faced by conventional fuzzy logic systems is the exponential increase in the number of rules, along with growth in number of variables entering into the system. It becomes difficult to tackle a large number of rules and it has great influence on the performance of the system. The proposed model reduces the total number of parameters in the mathematical formulas of fuzzy systems. The total number of rules increases exponentially in the mathematical formula of fuzzy systems with the number of input variables. Hence, to avoid the exponential increment in the mathematical formula of fuzzy systems when new parameters enter into the systems the integrated hierarchical fuzzy model is proposed.

\subsubsection{Data or Information Reduction}

The number of data or knowledge set required for fuzzy systems identification increases exponentially with the number of input variables. The proposed system also reduces the number of data or knowledge set required to identify fuzzy systems. As a minor error in rule design may lead to uncertain results, therefore, rule design is time consuming and requires attention. In case of a high number of variables, the probability of error also increases. It becomes extremely difficult to define the system when the number of rules increases to a certain number. Differentiating between the rules supplied by an expert and rules learned from examples becomes difficult.

\subsubsection{Rule Specification}

Rule specification is also important while designing rules in the rule base of Mamdani fuzzy logic. Rule specification requires a lot of experience and experts are required to specify rules; while discussing this problem in this study, we have also introduced two rule specification methods: namely, maximum rule-based and average rule-based. The introduced rule specification methods may assist the manager in rule design according to the system requirement.

\section{Conclusions and Future Work}

In this paper, a novel integrated hierarchical fuzzy logic for calculating the underground risk index was proposed. The proposed approach tackles the issues (the exponential increase of rules as new variables enter into the system and also the lake of rule designing schemes) faced by conventional fuzzy logic risk assessment frameworks. The main advantage of the proposed method is the simple 
structure of the hierarchical fuzzy model for the underground risk index calculation using eight input parameters. In this method, the numbers of rules do not increase exponentially as new variables enter into the system. In this study, we also proposed new rules designing schemes, namely, average rule-based and maximum rule-based schemes to help experts while designing rules. The model is the best choice for a risk index calculation with a lot of input parameters, because it is less computationally complex. In the future, we may add more input parameters to the existing model and develop more rule design schemes.

Acknowledgments: This work was supported by the National Research Council of Science \& Technology (NST) grant by the Korea government (MSIP) (No. CRC-14-02-ETRI). And this research was supported by the MSIT (Ministry of Science and ICT), Korea, under the ITRC (Information Technology Research Center) support program (IITP-2017-2014-0-00743) supervised by the IITP (Institute for Information \& communications Technology Promotion). Any correspondence related to this paper should be addressed to DoHyeun Kim.

Author Contributions: Muhammad Fayaz conceived the idea for this paper, designed the experiments and wrote the paper; Israr Ullah assisted in model designing and experiments. Dong-Hwan Park, Kwangsoo Kim and DoHyeun Kim conceived the overall idea of underground risk assessment, and proof-read the manuscript.

Conflicts of Interest: The authors declare no conflict of interest

\section{References}

1. Sturk, R.; Olsson, L.; Johansson, J. Risk and decision analysis for large underground projects, as applied to the Stockholm ring road tunnels. Tunn. Undergr. Space Technol. 1996, 11, 157-164. [CrossRef]

2. Huang, G.; Chen, Z.; Tontiwachwuthikul, P.; Chakma, A. Environmental risk assessment for underground storage tanks through an interval parameter fuzzy relation analysis approach. Energy Sources 1999, 21, 75-96.

3. Paolucci, R.; Pitilakis, K. Seismic risk assessment of underground structures under transient ground deformations. In Proceedings of the 4th International Conference on Earthquake Geotechnical Engineering-Invited Lectures, Thessaloniki, Greece, 25-28 June 2007; pp. 433-459.

4. Wang, Y.-M.; Elhag, T.M. An adaptive neuro-fuzzy inference system for bridge risk assessment. Exp. Syst. Appl. 2008, 34, 3099-3106. [CrossRef]

5. Pokoradi, L. Fuzzy logic-based risk assessment. AARMS Acad. Appl. Res. Mil. Sci. 2002, 1, 63-73.

6. Markowski, A.S.; Mannan, M.S. Fuzzy logic for piping risk assessment (pfLOPA). J. Loss Prev. Process Ind. 2009, 22, 921-927. [CrossRef]

7. Arabacioglu, B.C. Using fuzzy inference system for architectural space analysis. Appl. Soft Comput. 2010, 10, 926-937. [CrossRef]

8. Lee, M.-L.; Chung, H.-Y.; Yu, F.-M. Modeling of hierarchical fuzzy systems. Fuzzy Sets Syst. 2003, 138, 343-361. [CrossRef]

9. Jelleli, T.M.; Alimi, A.M. Automatic design of a least complicated hierarchical fuzzy system. In Proceedings of the International Conference on Fuzzy Systems, Barcelona, Spain, 18-23 July 2010; pp. 1-7.

10. Zaidi, A.; Rokbani, N.; Alimi, A. Implementation of a hierarchical fuzzy controller for a biped robot. arXiv, 2014.

11. Kleta, H.; Heyduk, A. Image processing and analysis as a diagnostic tool for an underground infrastructure technical condition monitoring. In Underground Infrastructure of Urban Areas 3; Taylor \& Francis Group: London, UK, 2014; p. 39.

12. Lej, K. The technical and economic conditions for the construction of the central section of metro line II in Warsaw. In Underground Infrastructure of Urban Areas 3; Taylor \& Francis Group: London, UK, 2014; p. 85.

13. Kuttisseril, J.; Kuang, K. Development of a low-cost image processing technique for crack detection for structural health monitoring. In Proceedings of the 3rd ASEAN Australian Engineering Congress (AAEC 2015): Australian Engineering Congress on Innovative Technologies for Sustainable Development and Renewable Energy, Engineers, Singapore, 11-13 March 2015; p. 55.

14. Sun, M.H.; Zhao, Y.X.; Jiang, W.; Feng, T.T. A scheme for excavation displacement monitoring based on image processing. In Applied Mechanics and Materials; Trans Tech Publications: Stafa-Zurich, Switzerland, 2012; pp. 1923-1926.

15. Jahanshahi, M.R.; Masri, S.F. Adaptive vision-based crack detection using 3D scene reconstruction for condition assessment of structures. Autom. Constr. 2012, 22, 567-576. [CrossRef] 
16. Qi, D.; Liu, Y.; Wu, X.; Zhang, Z. An algorithm to detect the crack in the tunnel based on the image processing. In Proceedings of the 2014 Tenth International Conference on Intelligent Information Hiding and Multimedia Signal Processing, Kitakyushu, Japan, 27-29 August 2014; pp. 860-863.

17. Meng, Q.; Wang, X.; Qu, X.; Yong, K.; Lee, S.; Wong, S. Quantitative risk assessment models of road tunnels-state of the art and their implications for singapore's road tunnels. In Proceedings of the 2nd International Tunnel Safety Forum for Road and Rail, Lyon, France, 20-21 April 2009; pp. 20-22.

18. Zhang, X.; Yan, S. Event tree analysis for steam generator tube ruptures. Nucl. Power Eng. 1999, 20, 168-173.

19. Meng, Q.; Qu, X.; Wang, X.; Yuanita, V.; Wong, S.C. Quantitative risk assessment modeling for nonhomogeneous urban road tunnels. Risk Anal. 2011, 31, 382-403. [CrossRef] [PubMed]

20. Blockley, D. Predicting the likelihood of structural accidents. Proc. Inst. Civ. Eng. 1975, 59, 659-668. [CrossRef]

21. Cho, H.-N.; Choi, H.-H.; Kim, Y.-B. A risk assessment methodology for incorporating uncertainties using fuzzy concepts. Reliab. Eng. Syst. Saf. 2002, 78, 173-183. [CrossRef]

22. Fujino, T. The Development of a Method for Investigating Construction Site Accidents Using Fuzzy Fault Tree Analysis. Ph.D. Thesis, The Ohio State University, Columbus, OH, USA, 1994.

23. Kim, K.; Park, D.-H.; Lee, J.; Jin, S.-I. Ugs middleware for monitoring state of underground utilities. In Proceedings of the 2015 International Conference on Information and Communication Technology Convergence (ICTC), Jeju, Korea, 28-30 October 2015; pp. 1183-1185.

24. Mamdani, E.H.; Assilian, S. An experiment in linguistic synthesis with a fuzzy logic controller. Int. J. Man-Mach. Stud. 1975, 7, 1-13. [CrossRef]

25. Zhao, J.; Bose, B.K. Evaluation of membership functions for fuzzy logic controlled induction motor drive. In Proceedings of the IEEE 2002 28th Annual Conference of the Industrial Electronics Society (IECON 02), Sevilla, Spain, 5-8 November 2002; pp. 229-234.

(C) 2017 by the authors. Licensee MDPI, Basel, Switzerland. This article is an open access article distributed under the terms and conditions of the Creative Commons Attribution (CC BY) license (http:/ / creativecommons.org/licenses/by/4.0/). 